\title{
Chaos terrain, storms, and past climate on Mars
}

\author{
Edwin S. Kite, ${ }^{1,2}$ Scot Rafkin, ${ }^{3}$ Timothy I. Michaels, ${ }^{3}$ William E. Dietrich, ${ }^{1}$ \\ and Michael Manga ${ }^{1,2}$ \\ Received 31 December 2010; revised 25 May 2011; accepted 8 July 2011; published 11 October 2011.
}

[1] We model the atmospheric response to a chaos-forming event at Juventae Chasma, north of Valles Marineris, Mars, using the Mars Regional Atmospheric Modeling System (MRAMS). Interactions between lake-driven convergence, topography, and the regional wind field steer lake-induced precipitation to the southwest. Mean snowfall reaches a maximum of $0.9 \mathrm{~mm} / \mathrm{h}$ water equivalent (peak snowfall $1.7 \mathrm{~mm} / \mathrm{h}$ water equivalent) on the SW rim of the chasm. More than $80 \%$ of vapor released by the lake is trapped in or next to the lake as snow. Radiative effects of the thick cloud cover raise mean plateau surface temperature by up to $18 \mathrm{~K}$ locally. We find that the area of maximum modeled precipitation corresponds to the mapped Juventae plateau channel networks. At Echus Chasma, modeled precipitation maxima also correspond to mapped plateau channel networks. This is consistent with the earlier suggestion that Valles Marineris plateau layered deposits and interbedded channel networks result from localized precipitation. However, snowpack thermal modeling shows temperatures below freezing for the 12 mbar $\mathrm{CO}_{2}$ atmosphere used in our MRAMS simulations. This is true even for the most favorable orbital conditions, and whether or not the greenhouse effect of the lake storm is included. Moderately higher $\mathrm{CO}_{2}$ pressures, or non- $\mathrm{CO}_{2}$ greenhouse forcing, is very likely required for melting and plateau channel network formation under a faint young Sun. Required warming is $\leq 10 \mathrm{~K}$ : global temperatures need not be higher than today. In these localized precipitation scenarios, the rest of the planet remains dry.

Citation: Kite, E. S., S. Rafkin, T. I. Michaels, W. E. Dietrich, and M. Manga (2011), Chaos terrain, storms, and past climate on Mars, J. Geophys. Res., 116, E10002, doi:10.1029/2010JE003792.

\section{Introduction}

[2] The highlands of Mars show both erosional and depositional evidence for past fluvial flow, and geochemical and textural evidence at Meridiani indicates these features were formed by liquid water [Malin and Edgett, 2003; Kraal et al., 2008a; Murchie et al., 2009a; Grotzinger et al., 2006; McLennan and Grotzinger, 2008]. The distribution of fans and valleys with elevation, together with their morphology and inferred discharge, argue against groundwater as the sole source, and demand precipitation [Craddock and Howard, 2002; Carr and Head, 2003, 2010; Hynek and Phillips, 2003]. Three models may explain these observations. (1) A globally prolonged climate interval that intermittently allowed surface runoff is the most straightforward interpretation, and one that can draw on arid and polar Earth analogs [Pollack et al., 1987; Craddock and Howard, 2002; Forsberg-Taylor et al., 2004; Halevy et al., 2007; Barnhart

\footnotetext{
${ }^{1}$ Department of Earth and Planetary Science, University of California Berkeley, California, USA.

${ }^{2}$ Center for Integrative Planetary Science, University of California, Berkeley, California, USA.

${ }^{3}$ Department of Space Studies, Southwest Research Institute, Boulder, Colorado, USA.

Copyright 2011 by the American Geophysical Union. 0148-0227/11/2010JE003792
}

et al., 2009]. (2) Water vaporized by large impacts would briefly warm the global atmosphere, and precipitation from these transient water vapor greenhouse atmospheres could cut some valleys where there is evidence of rapid discharge [Segura et al., 2002, 2008; Kraal et al., 2008b; Toon et al., 2010]. (3) Localized precipitation in a globally cold/dry atmosphere is an alternative to global wet conditions. Triggers for localized precipitation could include groundwater outbursts, volcanic plumes, or medium-sized impacts [Mangold et al., 2008; Segura et al., 2008]. At least after the Noachian, valleys are patchily distributed [Williams, 2007; Weitz et al., 2008; Fassett and Head, 2008a; Hynek et al., 2010; Carr and Malin, 2000], which is consistent with localized precipitation.

[3] Localized precipitation is especially attractive as an explanation for $3.0 \mathrm{Ga}$ valleys exposed by aeolian erosion of layered deposits on the plateaus around the Valles Marineris plateau [Mangold et al., 2004; Weitz et al., 2008], and also $\sim 10 \mathrm{Ma}$ fans at Mojave Crater [Williams and Malin, 2008]. That is because these channels and fans postdate the sharp decline in globally averaged erosion rates, aqueous alteration, and channel formation near the Noachian - Hesperian boundary [Murchie et al., 2009a; Fassett and Head, 2008b; Golombek et al., 2006]. The rarity of channels, fans, fluvial erosion, or aqueous minerals of similar age suggests that the Valles Marineris plateau channel networks and Mojave Crater 

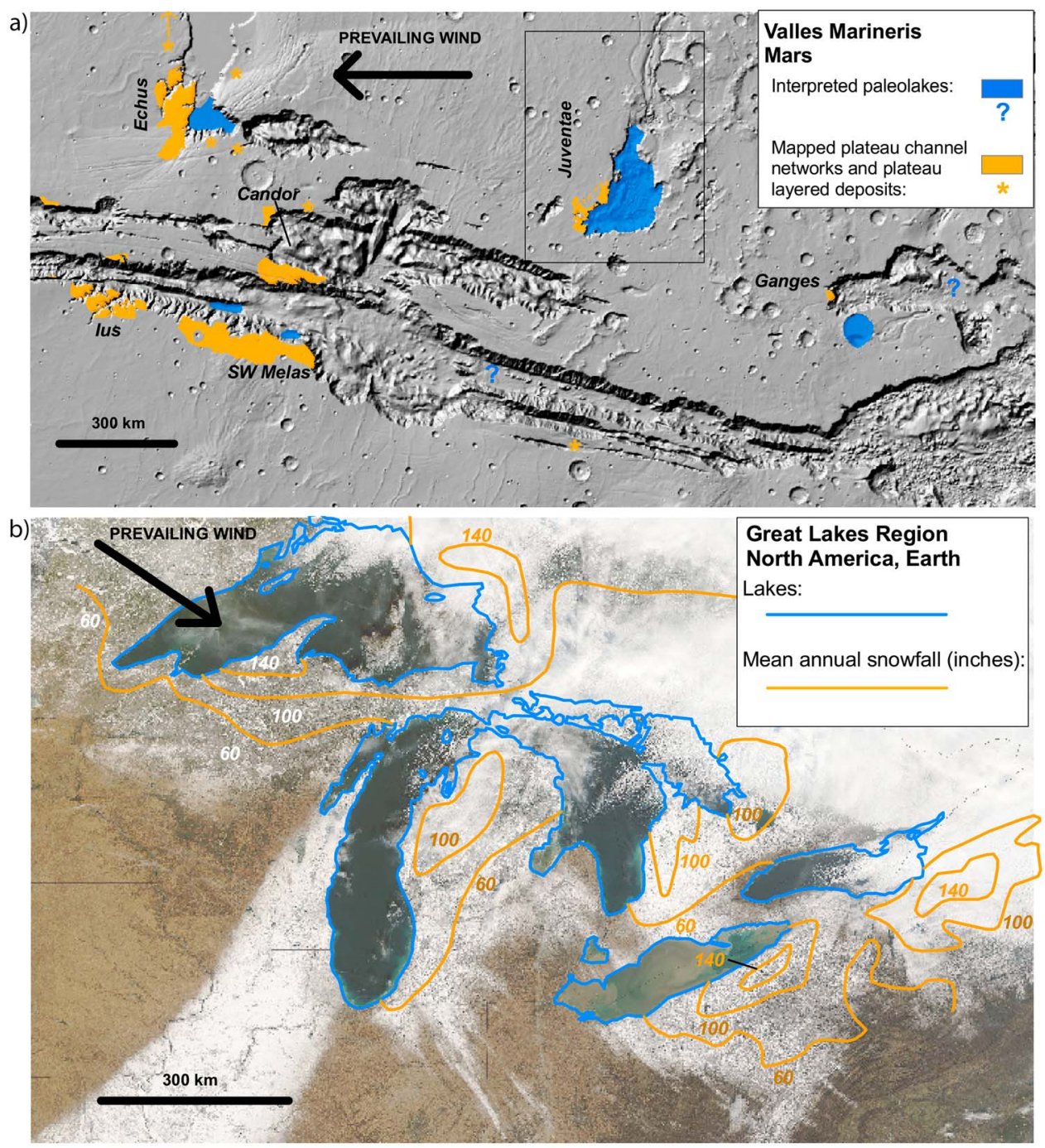

Figure 1. (a) Location of Valles Marineris plateau layered deposits and plateau channel networks downwind of paleolakes. Reported plateau layered deposits and channel networks are shown by orange shading. Asterisks correspond to isolated, or incompletely mapped, occurrences. Reported paleolakes are shaded in blue: those where we consider the evidence to be less strong are shown by question marks. Box around Juventae corresponds to Figure 4. Background is MOLA shaded relief. Sources are Weitz et al. [2010] (SW Melas, S Ius, S flank W Candor, Juventae and Ganges layered deposits); Le Deit et al. [2010] (N Ius, N flank W Candor, N Tithonium and Juventae layered deposits); Mangold et al. [2008] (Echus networks); Williams et al. [2005] (Candor channel); Harrison and Chapman [2008] (questionable Candor lake); Harrison and Grimm [2008] (Juventae and Echus lakes); Metz et al. [2009] (SW Melas lake); Roach et al. [2010] (Ius closed evaporitic basin); Komatsu et al. [2009] (Morella lake); and Carr [1995] (questionable Ganges lake). (b) Location of snowbelts downwind of the Great Lakes, North America, Earth. Each local maximum in mean annual snowfall, as shown by orange contours, is downwind of a lake. Snowbelts form from the cumulative effect of lake-effect storms. Contours are from Eichenlaub [1979], as reproduced by Markowksi and Richardson [2010]. The prevailing wind direction is shown by the black arrow and by the snow streaks in the background image. Background image was acquired 9 December 2006 by Terra/MODIS and shows the effects of a lake-effect storm on 7-8 December 2006 (image credit: NASA GSFC/Earth Observatory).

fans do not record global episodes of surface runoff. Localized precipitation is an alternative, with vapor sourced from a transient event such as groundwater release during chaos terrain formation (at Valles Marineris) or partial melting of an ice-silicate mixture during impact (at Mojave Crater). Simulations relevant to impact-induced localized precipitation have been reported in several conference abstracts [e.g., Segura and Colaprete, 2009] and a thesis chapter [Plesko, 2009]. Baker et al. [1991] suggest that vapor release during outflow channel formation has global effects. Valles Marineris localized precipitation has been suggested previously [Gulick and Baker, 1989; Baker et al., 


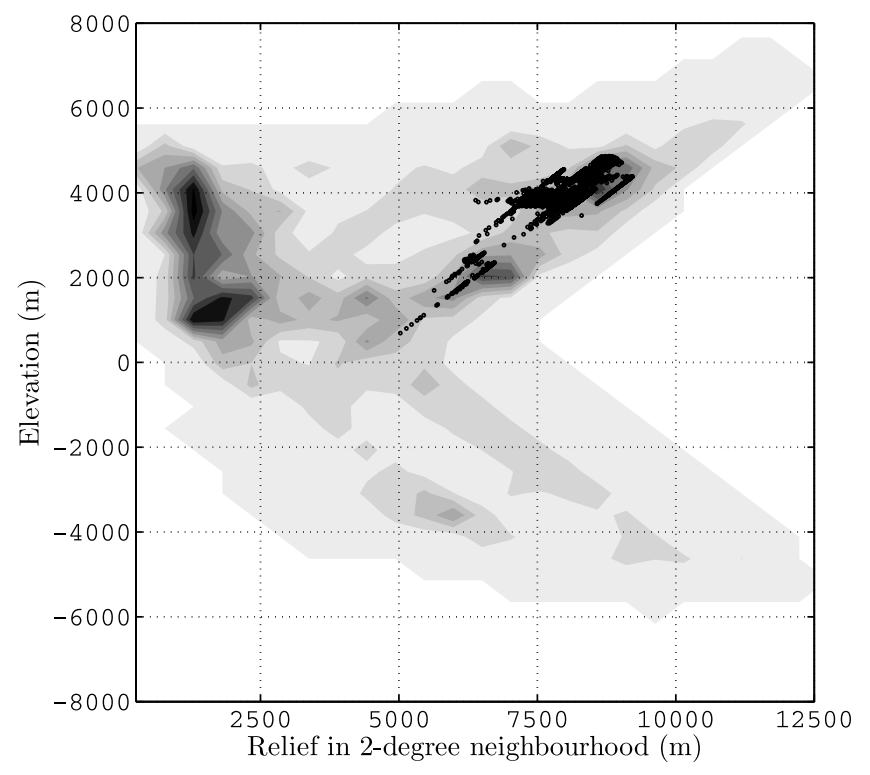

Figure 2. Topographic context of inverted channels. Black dots correspond to points mapped as "light-toned layered deposit" or "inverted channel" by Weitz et al. [2010]. The association of inverted channels with light-toned layered deposits containing opal \pm jarosite is only found near the rims of large canyons. Gray scale background is the probability distribution of all points, using a bin size of $500 \mathrm{~m}$. Relief at a point is defined as the maximum difference in elevation between that point and all other points in a neighborhood with 2-degree radius. (With this definition, points with intermediate elevation cannot have high relief.)

1991; Mangold et al., 2008; Williams and Malin, 2008], and Santiago et al. [2005, 2006] report preliminary General Circulation Model (GCM) simulations of atmospheric response to outflow channel flooding. Mesoscale effects of the outflow response have not been studied previously.

[4] Here we investigate the well-preserved layered deposits with interbedded channel networks on the Valles Marineris plateau west of Juventae Chasma [Malin et al., 2010; Weitz et al., 2010]. Our goal is to understand these deposits and use them as a proxy for past Mars climate. Our approach iterates between modeling and geology. According to Malin et al. [2010, p. 32] the Juventae plateau networks include "hillslope rills and low order streams," leading Malin et al. [2010, p. 38] to describe them as "the best evidence yet found on Mars to indicate that rainfall and surface runoff occurred." In sections 2 and 3, we summarize geologic observations: some constitute boundary conditions for the model, others are targets that the model must reproduce in order to be considered successful. In section 4 we analyze results from Mars Regional Atmospheric Modeling System (MRAMS) [Rafkin et al., 2001; Michaels et al., 2006] simulations of chaos flood-effect precipitation that include detailed cloud microphysics (Appendix A). We find excellent agreement between the model-predicted precipitation locations and the previously mapped area of layered deposits and inverted channel networks (statistical analysis in Appendix B). In this paper, we concentrate on what controls the rate and location of precipitation. The companion paper by Kite et al. [2011] (hereafter referred to as paper 1) describes idealized simula- tions of cloud formation and precipitation in a thin, cold atmosphere perturbed by a lake. Precipitation in our model falls as snow, but the geologic observations demand liquid water runoff. Snowpack melting on the Juventae plateau will occur under certain combinations of orbital parameters and snowpack physical properties. These are determined (section 5 and Appendix C) by running a simple snowpack thermal model over all seasons, pressures from 12 to 195 mbar, all relevant solar luminosities, and for the full range of orbital conditions sampled by the chaotic diffusion of Mars' orbital parameters [Laskar et al., 2004]. We calculate the probability that snowpack melting will occur as a function of solar luminosity and additional greenhouse effect. In section 6, we evaluate multiple working hypotheses for the mechanism of channel formation, using measurements from our HiRISE Digital Terrain Models (DTMs; Appendix D). These measurements are from a small number of key localities on the Juventae Plateau. We do not attempt a comprehensive geologic analysis. Finally, we test the localized-precipitation hypothesis at a second site, Echus Chasma (section 7), and consider the implications of localized precipitation for global excursions to conditions warmer than the present-day on Hesperian Mars (section 8).

\section{Geologic Constraints: Valles Marineris Plateau Channel Networks}

[5] The Valles Marineris plateau layered deposits are distinct from layered deposits elsewhere on Mars [Weitz et al., 2008; Murchie et al., 2009a; Weitz et al., 2010]. Dendritic channels with both positive and negative relief are commonly found in association with the plateau layered deposits [Malin and Edgett, 2003; Edgett, 2005; Williams et al., 2005], with preserved drainage densities as high as $15 \mathrm{~km}^{-1}$ and commonly $>1 \mathrm{~km}^{-1}$. In contrast, most Mars light-toned layered deposits (LLD) have few or no channels visible from orbit. Channels at different levels within the plateau layered deposits crosscut one another [Weitz et al., 2010]. This requires that plateau channel formation was either interspersed with, or synchronous with, the depositional events that formed the layers. It suggests a common geologic scenario for channel formation and plateau layered deposit formation. Opal ( \pm hydroxylated ferric sulfate) has been reported in the plateau layered deposits [Milliken et al., 2008; Bishop et al., 2009], whereas most Mars LLD show sulfate ( \pm hematite \pm phyllosilicates) [Murchie et al., 2009a]. Plateau layered deposits show no evidence for regular bedding. Most LLD, in contrast, give the visual impression of quasiperiodic bedding, and this has been statistically confirmed at many locations [Lewis et al., 2008, 2010]. Because the most likely pacemaker for quasiperiodic sedimentation is orbital forcing [Kuiper et al., 2008; Lewis et al., 2008], this suggests the process that formed the plateau layered deposits was not sensitive to orbital forcing. Either stochastic processes controlled deposition, or deposition timescales were much shorter than orbital timescales [Lewis et al., 2010]. The deposits are $O\left(10^{1}\right) \mathrm{m}$ thick [Weitz et al., 2010], in contrast to the $O\left(10^{3}\right) \mathrm{m}$ of sulfate-bearing deposits within craters and canyons. Opaline plateau layered deposits overly early Hesperian lavas, placing them among the youngest classes of aqueous minerals on Mars [Murchie et al., 2009a]. They significantly postdate the maximum in valley formation 
a)

a) 0 INFERENCE FROM GEOLOGIC RELATIONS:

FORMATION OF PLATEAU CHANNELS AND PLATEAU LAYERED DEPOSITS IS RELATED TO CHASM OPENING (AND ASSOCIATED FLOODING)

1. SCENARIOS THAT COULD ACCOUNT FOR THIS RELATIONSHIP:
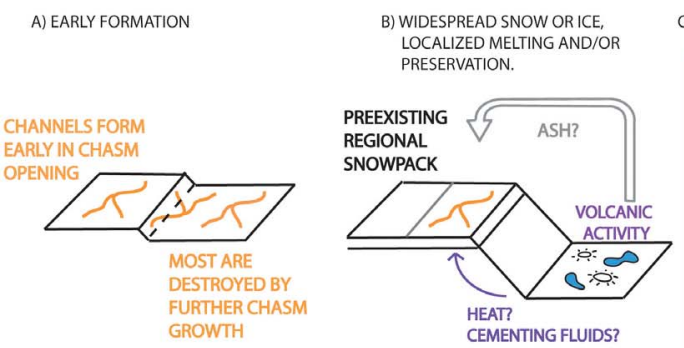

C) WATER-LIMITED FORMATION (PREFERRED SCENARIO)

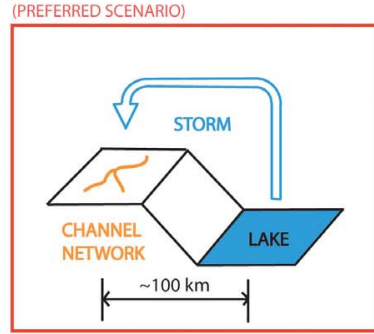

CEMENTING FLUIDS?

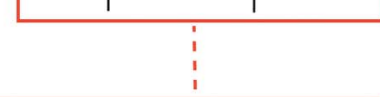

2.POSSIBLE CHANNEL-FORMING MECHANISMS WITHIN PREFERRED SCENARIO

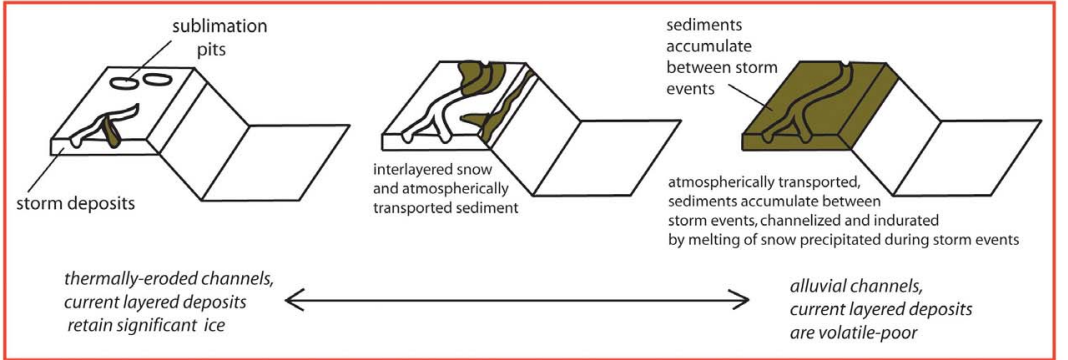

b)
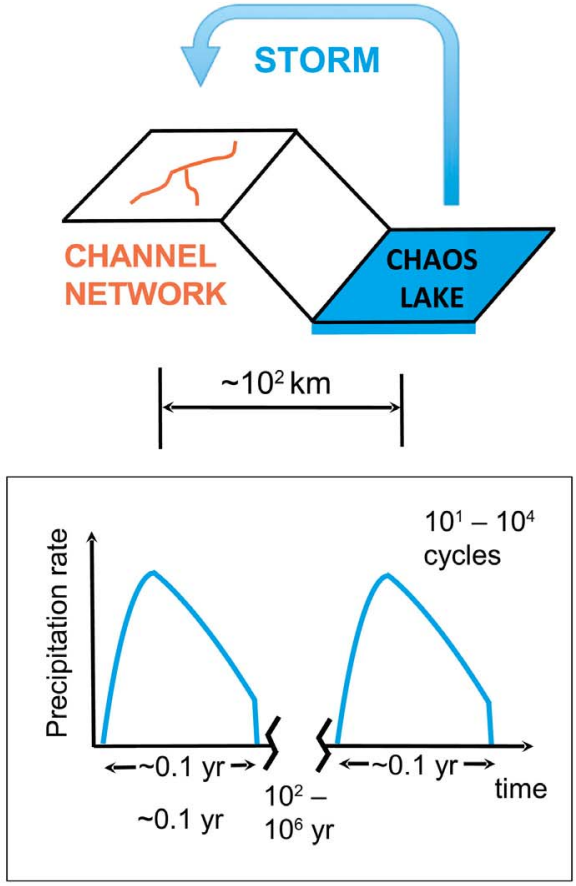

Figure 3. From geologic relations (section 2), we infer that the formation of plateau channel networks and plateau layered deposits is related to chasm opening (and associated flooding). (a) Sketch of scenarios that could account for this relationship. In our preferred scenario, condensation of vapor released from short-lived lake in chasm creates a snowstorm. Precipitation on the plateau next to the chasm forms channel networks. Precipitation falling back into the lake leaves no geomorphic signature. (b) Timescales implied by published models of chaos hydrology and the thermodynamics of lake freezing. Each lake event lasts $\leq 1$ year [Andrews-Hanna and Phillips, 2007; Harrison and Grimm, 2008]. Crosscutting channels, and discharge estimates from measurements of inner channels, require that many flood events occurred in each chaos chasm. Estimates of repose interval between groundwater outflow events center on $10^{2}-10^{6}$ years, and are considered to lengthen with time. Repose interval estimates are sensitive to poorly known crustal hydrologic properties [Andrews-Hanna and Phillips, 2007; Harrison and Grimm, 2008].

during the Late Noachian-Early Hesperian [Le Deit et al., 2010]. Taken together, these differences suggest the process which formed the Valles Marineris plateau layered deposits differed from that forming layered deposits elsewhere on Mars [Murchie et al., 2009a].

[6] Plateau layered deposits and inverted channels formed over an extended interval of time. Tilted channels are present on downdropped fault blocks [Le Deit et al., 2010], and some channels are truncated by chasm edges - therefore, some channels formed before backwasting of the chasm to its present-day form. Multiple periods of runoff are recorded on the plateau [Weitz et al., 2010].

[7] These observations raise several questions. What was the process that formed the plateau layered deposits? What was the source of the water for channel formation, and what permitted surface liquid water at this location? Does this require atmospheric pressures, temperatures, or water vapor loading different from contemporary Mars-and if so, are the required changes global, regional or local? What were the mechanics of channel formation - for example, are these mechanically eroded or thermally eroded channels? Our focus in this paper is on the first three questions, although we address channel formation mechanisms in section 6 .
[8] Channels are usually found on plateaux immediately adjacent to chasms. Location on a plateau immediately adjacent to a chasm apparently provided a driver (limiting factor) for channel formation and/or preservation (Figure 1a). For example, the Echus, Juventae and Ganges plateau channel networks are all immediately west (downwind) of inferred paleolakes (Figure 2) [Coleman and Baker, 2007; Harrison and Chapman, 2008]. A relief-elevation plot confirms, independently, that all plateau layered deposits are near the edge of a chasm (Figure 2). To form, a channel requires water supply sufficient to balance continuous losses to infiltration and evaporation, while generating runoff. Runoff must encounter sediment that is fine-grained enough to be mobilized. Inverted channels have additional requirements: to be exposed at the surface today, an inverted channel must be preferentially cemented or indurated, and then incompletely eroded. Therefore, there are five potential limiting factors for inverted channel formation: heat, water, sediment, cementing fluids, or erosion. Location downwind of a chasm should logically supply at least one.

[9] We hypothesize that the Juventae, Echus and Ganges plateau channel networks and layered deposits formed downwind of ephemeral chaos lakes, through precipitation 


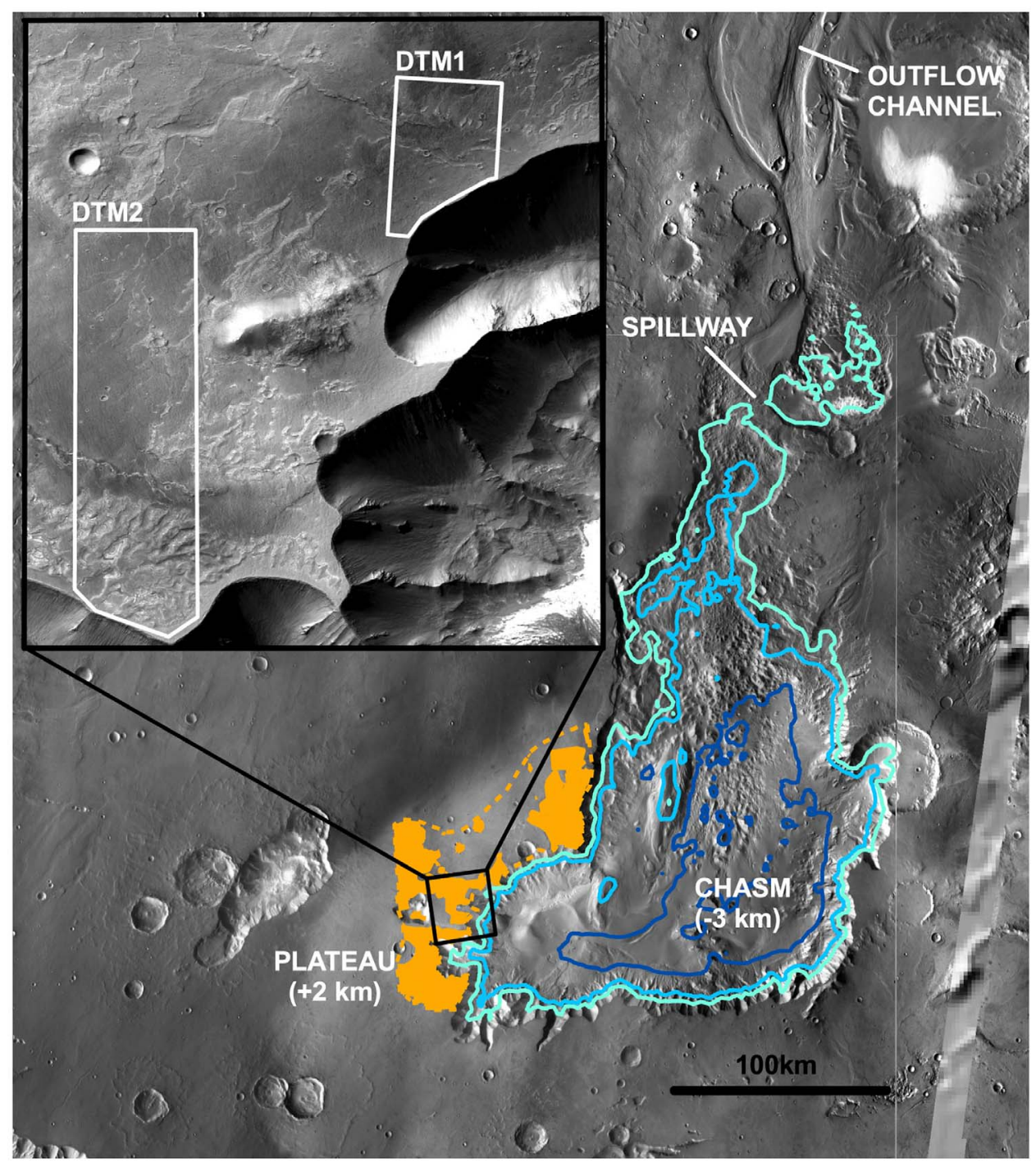

Figure 4. Site for our hypothesis test-Juventae. Juventae Chasma is a $5 \mathrm{~km}$ deep, sharp-sided chaos chasm that sources Maja Valles (outflow channel to N). Orange shading corresponds to the area of plateau channel networks and plateau layered deposits mapped by Le Deit et al. [2010]. Orange dotted line corresponds to pre-erosion extent estimated by Le Deit et al. [2010] from outliers. Spillway to N of chasm indicates that flood level exceeded $+1180 \mathrm{~m}$. We model flooding to depth $-3000 \mathrm{~m}$ (deep blue), $-1000 \mathrm{~m}$ (middle blue) and $+0 \mathrm{~m}$ (cyan). Main figure background is THEMIS VIS mosaic. Inset shows the locations of 2 HiRISE DTMs (Appendix D) that we constructed to characterize the inverted channel networks. Inset background is part of CTX image P18_007983_1751_XN_04S063W.

from lake-effect storms (paper 1 and Figure 3). In our hypothesis, rain or snow from nearby lakes is the limiting factor for forming plateau channels and light-toned deposits, explaining the spatial association between chasm lakes and plateau channels/light-toned deposits. This is analogous to the 'snowbelts' that form downwind of the Great Lakes of North America from the cumulative precipitation of lakeeffect storms (Figure 1b). Our hypothesis predicts that simulations of lake-effect storms in Valles Marineris should produce precipitation that is localized to the chasm rim and in the observed locations. We test our hypothesis at Juventae Chasma, because it has the best preserved plateau channels and the geologic evidence for a paleolake there is also compelling [Coleman and Baker, 2007; Harrison and Chapman,
2008]. Other possible scenarios for forming plateau channels and plateau layered deposits (Figure 3) are discussed in section 6 .

\section{Geologic Constraints: Boundary Conditions at Juventae Chasma}

[10] Juventae Chasma has a spillway at $\approx+1 \mathrm{~km}$ elevation that is connected to the Maja Vallis outflow channel [Catling et al., 2006; Coleman and Baker, 2007] (Figure 4). The floor of Juventae Chasma is below $-4 \mathrm{~km}$. Insofar as material was removed from the chasm by fluvial or debrisflow transport across the spillway, this suggests that a lake many $\mathrm{km}$ deep existed at least once in Juventae Chasma 


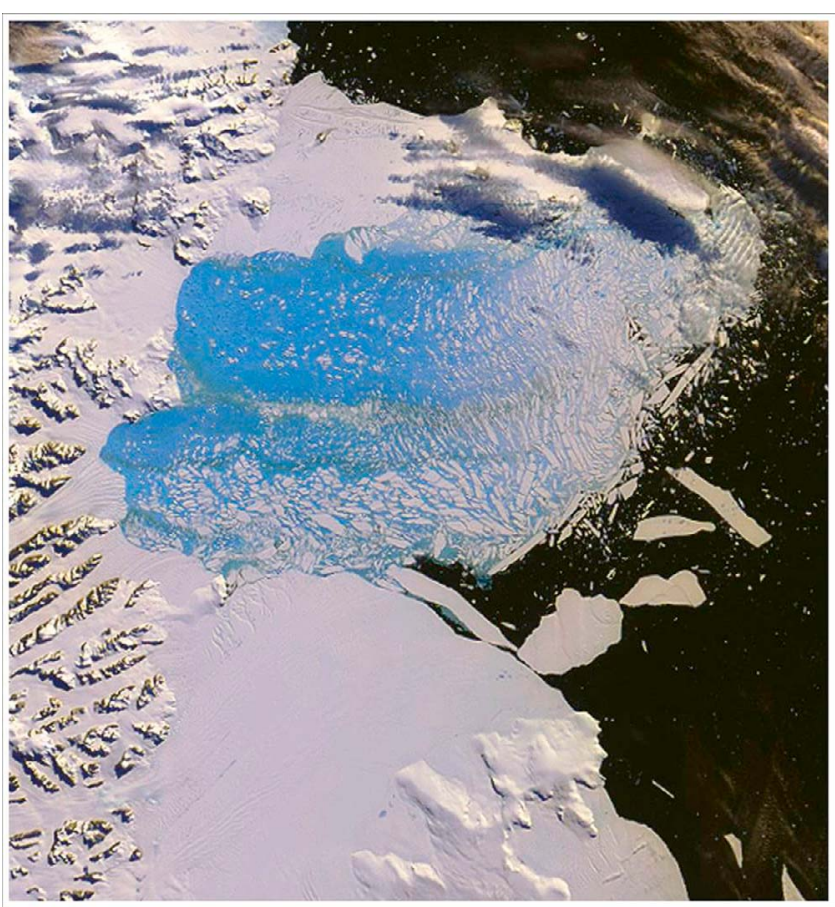

Figure 5. Disintegration of Antarctica's Larsen B ice shelf. Collapsed area is $\sim 3000 \mathrm{~km}^{2}$. Acquired 7 March 2002 by Terra/MODIS. Image credit: NASA GSFC.

[Coleman and Baker, 2007]. Evidence that multiple outbursts cut Maja Vallis also suggests that Juventae Chasma was flooded multiple times [Harrison and Grimm, 2008].

[11] The duration of surface liquid water during groundwater outburst floods is unknown. It will depend partly on the peak discharge, which is set by the permeability of the source aquifer - another unknown. Harrison and Chapman [2008] calculate a duration of $0.1-10^{5}$ days per event, with $\leq 5 \times$ $10^{3}$ days per event preferred. The corresponding peak discharge rates range from $3 \times 10^{5} \mathrm{~m}^{3} \mathrm{~s}^{-1}$ to $10^{8} \mathrm{~m}^{3} \mathrm{~s}^{-1}$. When discharge falls below the evaporation rate, icing-over of the lake surface is increasingly likely. For the $140 \mathrm{~km}$-diameter cylindrical chaos modeled by Harrison and Chapman [2008], and an evaporation rate of $2 \mathrm{~mm} / \mathrm{h}$, the cryosphere fractures are frozen shut before the discharge falls below the evaporation rate. Alternatively, surface liquid water in a chaos terrain can be generated by failure of a dam confining an ice-covered lake, leading to mechanical disruption of the ice cover. For example, the 2002 stepwise collapse of Antarctica's Larsen B ice shelf took 3 weeks, with open water between collapsed ice blocks (Figure 5) [Scambos et al., 2003].
[12] Boundary conditions are as follows. We impose a lake temperature of $278.15 \mathrm{~K}\left(5^{\circ} \mathrm{C}\right)$, which is midway between dissipative throttling (Joule-Thompson) heating of aquifer water initially at $5 \mathrm{~km}$, and two-phase hydrostatic ascent [Gaidos and Marion, 2003]. However, for the largest lake simulated (JUVENTAE HIGH, Table 1), we set lake surface temperature to $273.15 \mathrm{~K}\left(0^{\circ} \mathrm{C}\right)$. This is because the high latent-energy flux associated with a large lake area at $278.15 \mathrm{~K}$ caused numerical instabilities in the model. We hold lake temperature steady. This is a reasonable assumption if the atmospheric response timescale (hours-days) is shorter than the timescale over which the chaos flood hydrograph changes, or if surface water continuously pours over the spillway, allowing the surface layer to be refreshed by warmer water from depth (see discussion in section 4.1.5). Wind-dependent lake surface roughness is from equation 7.21 of Pielke [2002]. The inverted streams at Juventae required surface liquid water to form, but currently the low atmospheric pressure at plateau elevation $(+2 \mathrm{~km})$ makes surface liquid water unstable [Conway et al., 2011]. Therefore, we doubled initial and boundary pressure throughout our simulation. We will show later (section 5) that still higher pressures are probably needed to suppress evaporative cooling and allow melting. We use present-day topography in our model, apart from flooding to the lake level within Juventae Chasma. (A minor exception is that we remove the sulfate-bearing [Bishop et al., 2009; Catling et al., 2006] light-toned layered deposits from within the chasm, which would otherwise form islands in our ephemeral lake. This is because we agree with the geologic interpretation that these deposits largely postdate chasm formation [Murchie et al., 2009b], although there is disagreement on this point [Catling et al., 2006]. The change has no effect on our best fit model (JUVENTAE HIGH) because, in our smoothed topography, the lake level in JUVENTAE_HIGH is higher than the summits of the sulfatebearing light-toned layered deposits.) We use present-day solar luminosity in our precipitation model (but not in our melting model; section 5). This is conservative in terms of localized precipitation, because lower atmospheric temperatures favor localized precipitation (paper 1). More details of the model setup are provided in Appendix A.

\section{Juventae Mesoscale Model: Precipitation Output}

[13] This paper reports the results of model runs that vary lake temperature and lake level (Table 1), holding orbital elements and obliquity at present-day values and fixing the season at simulation start to southern Summer $(\mathrm{Ls} \approx 270)$. An MRAMS run simulating 7 days at Valles Marineris takes

Table 1. List of Runs With Parameters

\begin{tabular}{lcccc}
\hline \multicolumn{1}{c}{ Run } & Full Name & Lake Level (m) & Lake Temperature (K) & Lake Area (km $\left.{ }^{2}\right)$ \\
\hline JUVENTAE_DRY & juventae_Mar_12_2010 & - & - & - \\
JUVENTAE_HIGH & juventae_May_12_2010 & +0 & 273.15 & Dalles Marineris topography, no lake \\
JUVENTAE_MED & juventae_Mar_13_2010 & -1000 & 278.15 & At spillway \\
JUVENTAE_LOW & juventae_Mar_14_2010 & -3000 & 278.15 & 19400 \\
ECHUS_LOW & echus_Apr_52010 & -900 & 278.15 & 6400 \\
ECHUS_HIGH & echus_Mar_25_2010 & -800 & 273.15 & 3600 \\
Almost fills chasm & In SE corner of chasm & Small equant lake \\
\hline
\end{tabular}



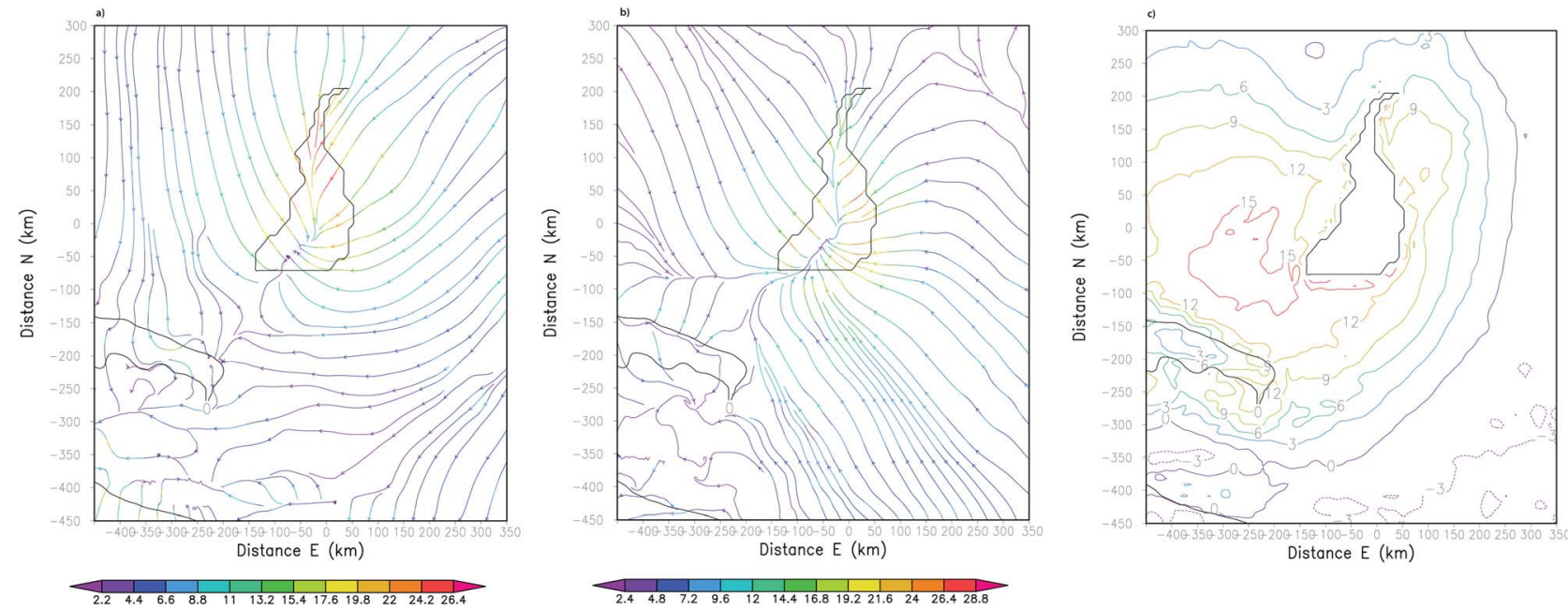

Figure 6. Temperature and wind field at Juventae in our best fit lake storm simulation (JUVENTAE_HIGH). $0 \mathrm{~m}$ contour (black) defines canyons. (a) Net time-averaged wind at $13 \mathrm{~m}$ elevation. Overall easterly and southeasterly winds are reversed at Juventae Chasma because of the lake-driven circulation. (b) Change in wind field due to the lake (differencing dry and wet runs). Lake storm drives low-level convergence of up to $30 \mathrm{~m} \mathrm{~s}^{-1}$. Magnitude of lake-driven circulation is comparable to magnitude of non-lake circulation. (c) Temperature difference due to lake. Temperature increases by up to $18 \mathrm{~K}$ downwind of lake. Axis tick labels correspond to distance from 3.91S 298.53E, near the lake center (average over 3 sols, from Mars hours 49 to 121$)$.

$\sim 0.5$ years to complete, so we are limited in the number of parameters we can vary. In addition, we must rerun the General Circulation Model (GCM) that supplies the mesoscale boundary conditions if we wish to model a major change in pressure or dust loading. This limits the range of sensitivity tests we can practicably apply. Paper 1 describes a wider range of sensitivity tests.

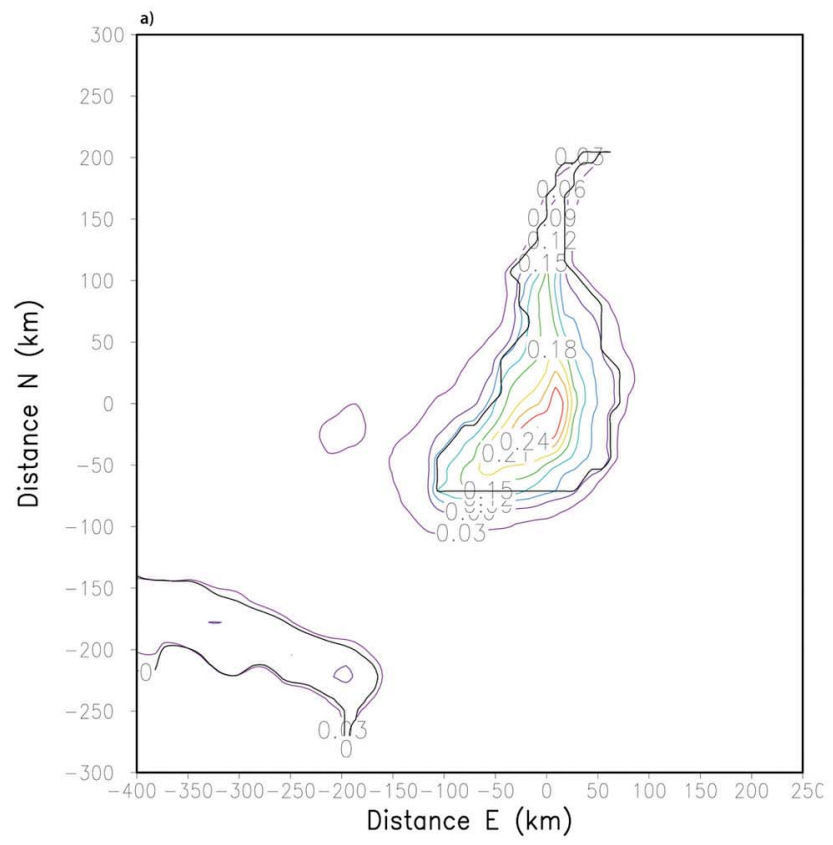

\subsection{Analysis of Best Fit Model}

[14] First we report results from our best fit model, JUVENTAE_HIGH.

4.1.1. Lake-Driven Convergence

[15] The lake perturbation to the atmosphere is superimposed on the complex, topographically driven Valles Marineris mesoscale windfield [Rafkin and Michaels, 2003;

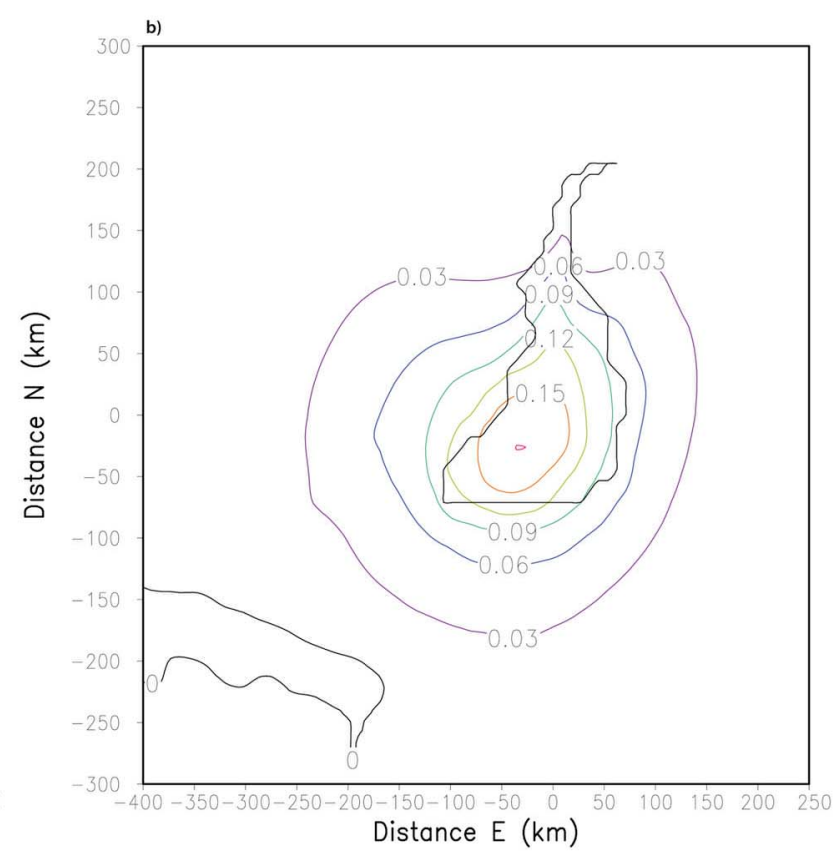

Figure 7. Ice and vapor columns at Juventae Chasma. (a) Time-averaged precipitable vapor column abundance, in $\mathrm{cm}$ water equivalent. (b) Time-averaged precipitable ice column abundance, in $\mathrm{cm}$ water equivalent. (JUVENTAE_HIGH, average for 3 sols, from Mars hours 49 to 121.) 


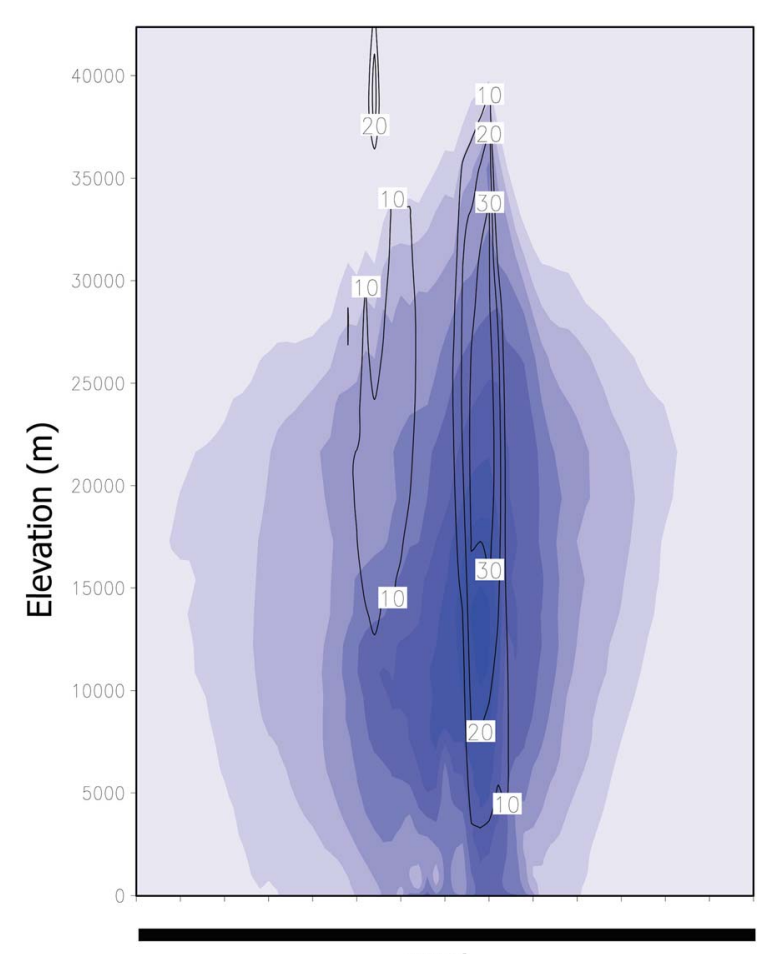

$581 \mathrm{~km}$

Figure 8. E-W cross section through lake storm. Blue tint corresponds to increasing water ice fraction (interval 0.001 , maximum value 0.009). Labeled contours correspond to bulk vertical velocity in $\mathrm{m} \mathrm{s}^{-1}$, which are comparable to the most intense supercell storms on Earth.

Spiga and Forget, 2009]. Strong slope winds are seen at Juventae Chasma in the JUVENTAE_DRY run, as previously described [Rafkin and Michaels, 2003; Spiga and Forget, 2009]. The diurnal cycle of upslope daytime winds and downslope nighttime winds is broken by the lake, which drives low-level convergence strong enough to overcome the upslope daytime wind (Figure 6b). At altitudes $<6 \mathrm{~km}$, the convergence is toward a sheet-like timeaveraged updraft running along the lake's long axis $(\mathrm{N}-\mathrm{S})$, and concentrated in the southern half of the lake. Above $10 \mathrm{~km}$, wind moves out from this updraft. East-directed outflow encounters the west-directed prevailing wind and slows, allowing more time for ice crystals to precipitate out before reaching the chasm edge. West-directed outflow is much faster. Above $20 \mathrm{~km}$, the windfield is increasingly dominated by radial flow away from a narrow, cylindrical updraft in the center of the lake. Lake storm effects on the background windfield are minor above $40 \mathrm{~km}$. A copious supply of water vapor, the availability of dust for ice nucleation, water vapor and cloud radiative effects, and induced low-level convergence combine to drive continuous precipitation.

\subsubsection{Radiative Effects}

[16] Mean temperature rises by $17 \mathrm{~K}$ downwind of the lake, where icy scatterers have precipitated but the greenhouse effect of vapor remains (Figure 6c). There is a broad region of $>5 \mathrm{~K}$ warming. On average, downwelling long- wave radiation increases by $60 \mathrm{~W} \mathrm{~m}^{-2} \mathrm{SW}$ of the deep pit that lies $\mathrm{W}$ of $\mathrm{S}$ Juventae. Ice cloud scattering partly compensates for this during the day, but maximum temperature also rises, by up to $8 \mathrm{~K}$, which is important for melting (section 5). However, in the area of greatest modeled precipitation, maximum temperature is reduced by up to $3 \mathrm{~K}$ because of the locally high atmospheric ice column abundance.

\subsubsection{Water Vapor and Ice Column Abundance}

[17] The time-averaged water vapor column abundance map (Figure 7a) shows that high vapor abundances are confined to the canyon. Ascent of vapor-laden parcels up canyon walls aids crystallization, and (ice column mass): (total water column mass) ratio increases from typically $<50 \%$ within Juventae Chasma to $60-70 \%$ on the plateau. Vapor is most abundant at low elevations. Peak precipitable vapor column abundance is $\sim 0.27 \mathrm{~cm}$ and is located slightly SW of the lake's areal centroid. The peak in time-averaged ice column abundance (Figure $7 \mathrm{~b}$ ) is shifted $30 \mathrm{~km}$ further WSW. This is the product of plume ascent timescales and the WSW-directed background wind speed (paper 1). Falloff of ice column abundance with distance from this peak is almost symmetric. This is because the outward-directed pressure gradient at the top of the buoyant plume is much stronger than that driving the background wind field. Maximum water ice column abundances away from the lake are above a promontory jutting into the lake on the SW edge of the chasm, and along the $\mathrm{S}$ edge of the chasm. These also correspond to the highest values of precipitation, as discussed below and shown in Figures 8, 9 and 10.

\subsubsection{Rate and Location of Snowfall}

[18] The footprint of precipitation is displaced downwind of the centroid of the lake by a distance similar to the product of vapor lifetime (loss due to ice crystal growth and subsequent gravitational sedimentation) and characteristic wind velocity at cloud height (Figure 10). Because the size of Juventae Chasma exceeds this distance, the peak in total precipitation $(1.3 \mathrm{~mm} / \mathrm{h}$ water equivalent, w.e.) lies within the lake. This prediction cannot be geologically tested, so we focus on results for precipitation on land.

[19] Most snow falls close to the chasm edge (Figure 9). Water-ice precipitation on the chasm flanks has a maximum on a promontory southwest of the lake center. Mean precipitation is $>0.6 \mathrm{~mm} / \mathrm{h}$ w.e. only in a narrow belt $<40 \mathrm{~km}$ from the chasm edge on the SW rim of the chasm. This area of high modeled precipitation corresponds to the mapped area of channels and layered deposits (Figure 9). In Appendix B, we use four independent metrics to quantify the agreement between geologic data and precipitation model that is qualitatively apparent in Figure 9.

[20] Reduction in snowfall with distance from the chasm is rapid (Figure B2). Decline is most rapid upwind (east) of the chasm. $200 \mathrm{~km}$ east of the chasm rim, peak snowfall and mean snowfall are both 1000 times less than at the chasm rim. Falloff is strongly modulated by topography: at a given distance from the lake, plateaux receive 10-100 times more snowfall than canyon floors.

[21] Maximum precipitation on land (not shown) is $1.7 \mathrm{~mm} / \mathrm{h}$ w.e. In the area of greatest mean precipitation, maximum precipitation is $1.5-2.0 \times$ the mean precipitation rate. Transient high snowfall during model spin-up is excluded. 


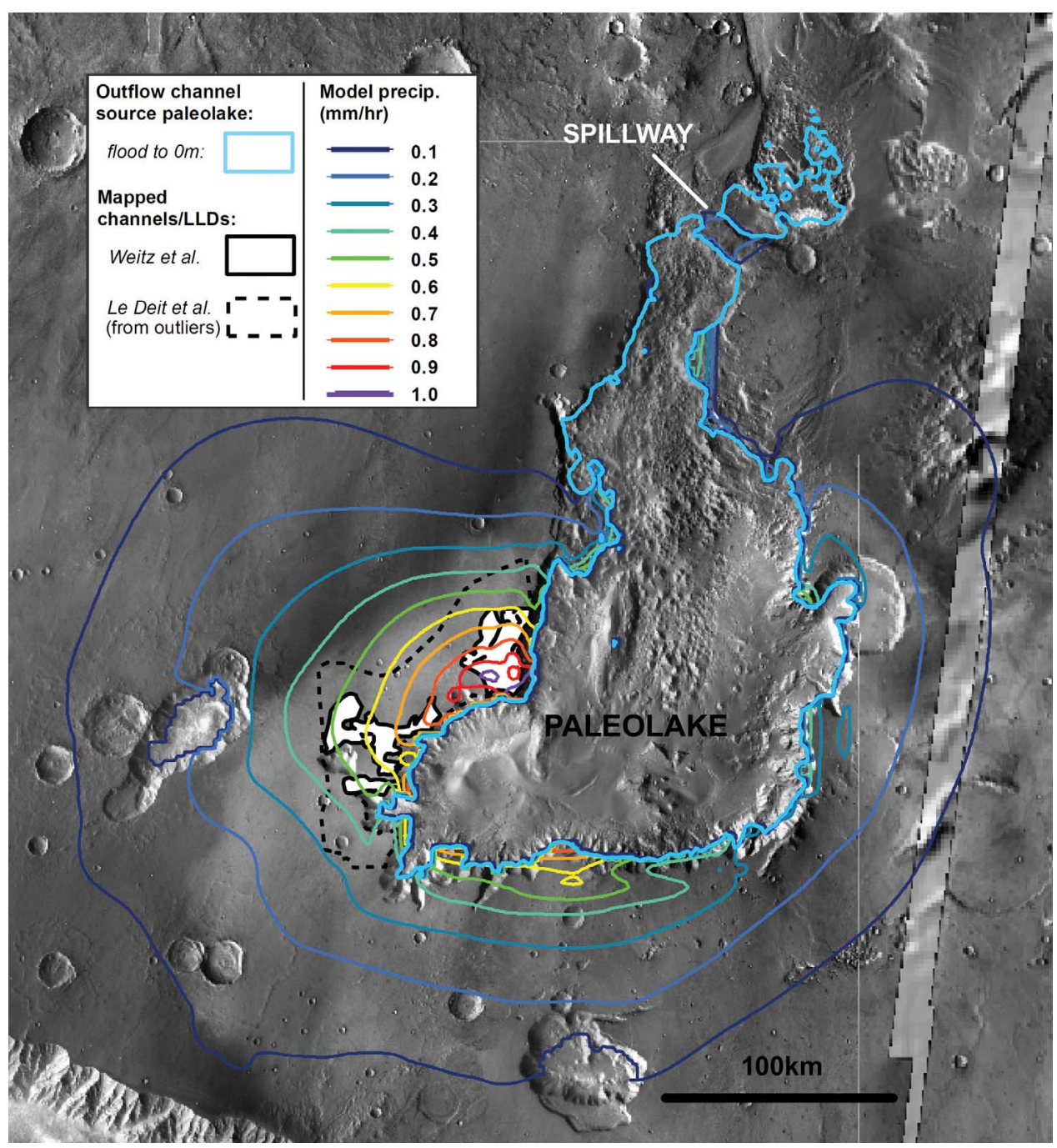

Figure 9. Modeled precipitation contours overlain on observed geology at Juventae. White shading with thick solid black outline corresponds to area of layered deposits and inverted channels reported by Weitz et al. [2010]. The dashed black outline corresponds to the pre-erosion area of layered deposits inferred from outlier buttes and pedestal craters by Le Deit et al. [2010]. The thick cyan line defines the flooded area for this simulation (the $-1000 \mathrm{~m}$ contour). The colored lines are modeled time-averaged precipitation contours at intervals of $0.1 \mathrm{~mm} / \mathrm{h}$ water equivalent. Precipitation falling back into the lake is not shown. The spatial maximum in mean precipitation is $\approx 1.0 \mathrm{~mm} / \mathrm{h}$. (Average for sol 5 of simulation.)

[22] The inflection in precipitation contours at the chasm edge (Figures 10 and 9) is a projection effect of the steep chasm wall slopes. Fall rates per unit column atmosphere decrease smoothly with distance from the lake, but at the chasm wall the snow from this column is spread over a larger surface area.

[23] Precipitation is localized and vapor lifetime is short, so precipitation rates are comparable to evaporation rates.

\subsubsection{Mass and Energy Budgets}

[24] Mean evaporation rates found from our mass balance ( $\sim 2 \mathrm{~mm} / \mathrm{h}$, Table 2) entail $1.4 \mathrm{~kW} / \mathrm{m}^{2}$ evaporative cooling. Is our assumption of constant lake surface temperature sustainable? An isolated, well-mixed lake of depth $5 \mathrm{~km}$ would cool only $0.006 \mathrm{~K} / \mathrm{sol}$ through evaporative cooling, so the assumption of constant lake surface temperature over the length of our simulations is reasonable in this case. The key is the depth of mixing. $1.4 \mathrm{~kW} / \mathrm{m}^{2}$ cannot be supplied from the interior of a liquid lake to its surface by conduction. Thermal convection may transfer the required heat if lake temperature is above water's temperature of maximum density $(277.13 \mathrm{~K})$ and

$$
q_{\text {convect }}=0.05\left(\frac{\rho g \alpha \Delta T}{\kappa \nu}\right)^{1 / 3} k \nabla T>1.4 \mathrm{~kW} / \mathrm{m}^{2}
$$

where $q_{\text {convect }}$ is convective heat flow in $\mathrm{W} / \mathrm{m}^{2}, \rho=$ $1000 \mathrm{~kg} / \mathrm{m}^{3}$ is water density, $g=3.7 \mathrm{~m} / \mathrm{s}^{2}$ is Mars gravity, $\alpha=2 \times 10^{-4} \mathrm{~K}^{-1}, \kappa=1.4 \times 10^{-7} \mathrm{~m}^{2} / \mathrm{s}, \nu=$ $10^{-6} \mathrm{~m}^{2} / \mathrm{s}, k=0.6 \mathrm{~W} / \mathrm{m} / \mathrm{K}$ is thermal conductivity, and $\nabla T$ is the temperature gradient across the lake [Postberg et al., 2009]. Even with $\nabla T=0.25 \mathrm{~K} / \mathrm{m}$ (very steep), $q_{\text {convect }}=180 \mathrm{~W} / \mathrm{m}^{2}$, insufficient to sustain evaporation. 

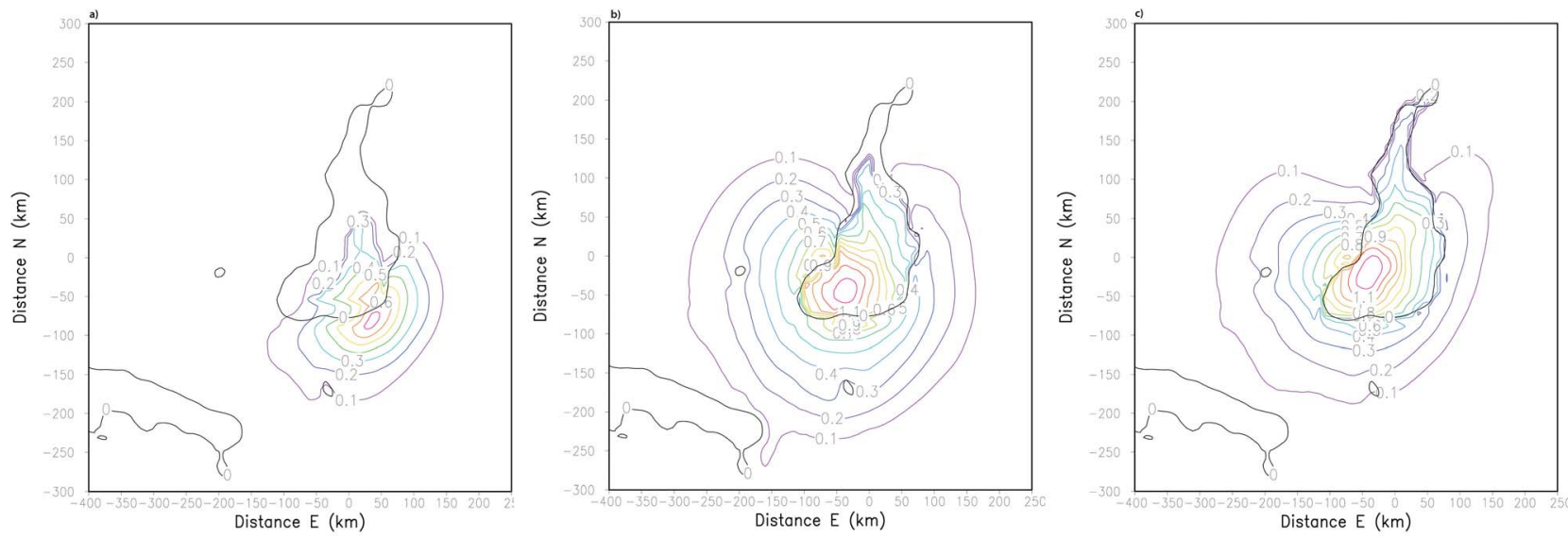

Figure 10. Sensitivity test comparing mean precipitation $(\mathrm{mm} / \mathrm{h})$ for three different lake levels: (a) $-3000 \mathrm{~m}$ (JUVENTAE_LOW), (b) -1000 m (JUVENTAE_MED), and (c) $0 \mathrm{~m}$ (JUVENTAE_HIGH).

[25] Therefore, if the lake did not freeze immediately, waves, bubbles or currents are required to stir the lake. This is reasonable, for example, if the aquifer was saturated with $\mathrm{CO}_{2}$ by a magmatic intrusion [Bargery and Wilson, 2010]. Also, the outflow itself could have disrupted the forming ice cover (Figure 5). For maximum Maja Valles outflow channel discharge $Q_{\text {maja }}=1.1 \times 10^{8} \mathrm{~m}^{3} \mathrm{~s}^{-1}$ [Kleinhans, 2005] and a lake surface area $A_{\text {lake }}=25800 \mathrm{~km}^{2}$ (Table 1), maintaining a steady lake surface elevation requires a vertical current $w \sim 4 \mathrm{~mm} / \mathrm{s}$ to the part of the lake above the spillway. The corresponding enthalpy flux to the upper part of the lake is $w \rho\left(c_{p}(T-273.15)+L_{\text {freeze }}\right)=1.42 \mathrm{MW} / \mathrm{m}^{2}$, much greater than evaporitic losses. Equivalently, suppose that we track a parcel of water that upwells near the center of the lake as it moves toward the spillway. Assume that the water lying above the spillway depth is well-stirred by currents flowing toward the spillway. Then cooling during the journey from the center of the lake to the spillway is

$$
\Delta T \approx 1.5 \mathrm{~kW} / \mathrm{m}^{2} \frac{A_{\text {lake }}}{\rho c_{p} Q_{\text {Maja }}} \sim 0.1 \mathrm{~K},
$$

which is small.

[26] Evaporitic loss from a fully open lake, $1.3 \times 10^{4} \mathrm{~m}^{3} \mathrm{~s}^{-1}$ $(=1.9 \mathrm{~mm} / \mathrm{h})$ in our best fitting model, is small compared to $\left.Q_{\text {Maja }}\right)$.
[27] We conclude that the liquid water surface imposed as a boundary condition for the mesoscale simulation is consistent with the simulation results, provided that catastrophic groundwater discharge continues as long as the lake storm persists.

\subsection{Sensitivity to Flooding Depth}

[28] The location of precipitation is sensitive to flooding depth, and flooding depths close to the spillway provide the best match to observations (Figure 10). As lake level rises, the offset of maximum precipitation from the lake center changes. The main change on land as the flooding depth is moved closer to the spillway is that precipitation to the $\mathrm{S}$ of Juventae Chasma is reduced. This is because the area of convergence shifts NW and then N, tracking the centroid of lake area.

[29] More than $80 \%$ of vapor released by the lake is trapped in or next to the lake as snow (Figure 11). As plume intensity increases, so does the fraction of water vapor that snows out locally. Plume intensity - which we define using updraft velocity and cloud height - increases with increasing lake size (paper 1) and with increasing lake temperature. Therefore, higher flooding depths within Juventae Chasma lead to more localized precipitation. Atmospheric water does increase with increasing lake area, but slowly (Table 2). Only JUVENTAE_LOW and JUVENTAE_MED are directly

Table 2. Evaporation Rate and Vapor Rate (End of sol 5) ${ }^{\mathrm{a}}$

\begin{tabular}{lcccccc}
\hline \multicolumn{1}{c}{ Run } & $\begin{array}{c}\text { Evaporation } \\
\text { Rate }(\mathrm{mm} / \mathrm{h})\end{array}$ & $\begin{array}{c}\text { Water in } \\
\text { Atmosphere }\end{array}$ & $\begin{array}{c}\text { Total } \\
\text { Atmosphere }(\%)\end{array}$ & $\begin{array}{c}\text { Snow in } \\
\text { Lake }\end{array}$ & $\begin{array}{c}\text { Snow Beyond } \\
\text { Lake }\end{array}$ & $\begin{array}{c}\text { Total } \\
\text { Snow (\%) }\end{array}$ \\
\hline JUVENTAE_DRY & 0 & 536 & $100 \%$ & 0 & 0 & $0 \%$ \\
JUVENTAE_LOW & 2.47 & 304 & 18 & 251 & 1166 & 82 \\
JUVENTAE_MED & 2.82 & 536 & 10 & 1356 & 3472 & 90 \\
JUVENTAE_HIGH & 1.88 & 571 & 12 & 1505 & 2590 & 88 \\
JUVENTAE_DRY_SOL_7 & 0 & 520 & 100 & 0 & & 0 \\
JUVENTAE_LOW_SOL_7 & 2.54 & 403 & 15 & 387 & 1887 & 85 \\
JUVENTAE_MED_SOL_7 & 2.90 & 658 & 8 & 2230 & 5393 & 92 \\
\hline
\end{tabular}

${ }^{\mathrm{a}}$ Units are Mt (10 $0^{6}$ metric tons). Italicized dry runs are subtracted from the runs below them. See also Figure 11. 


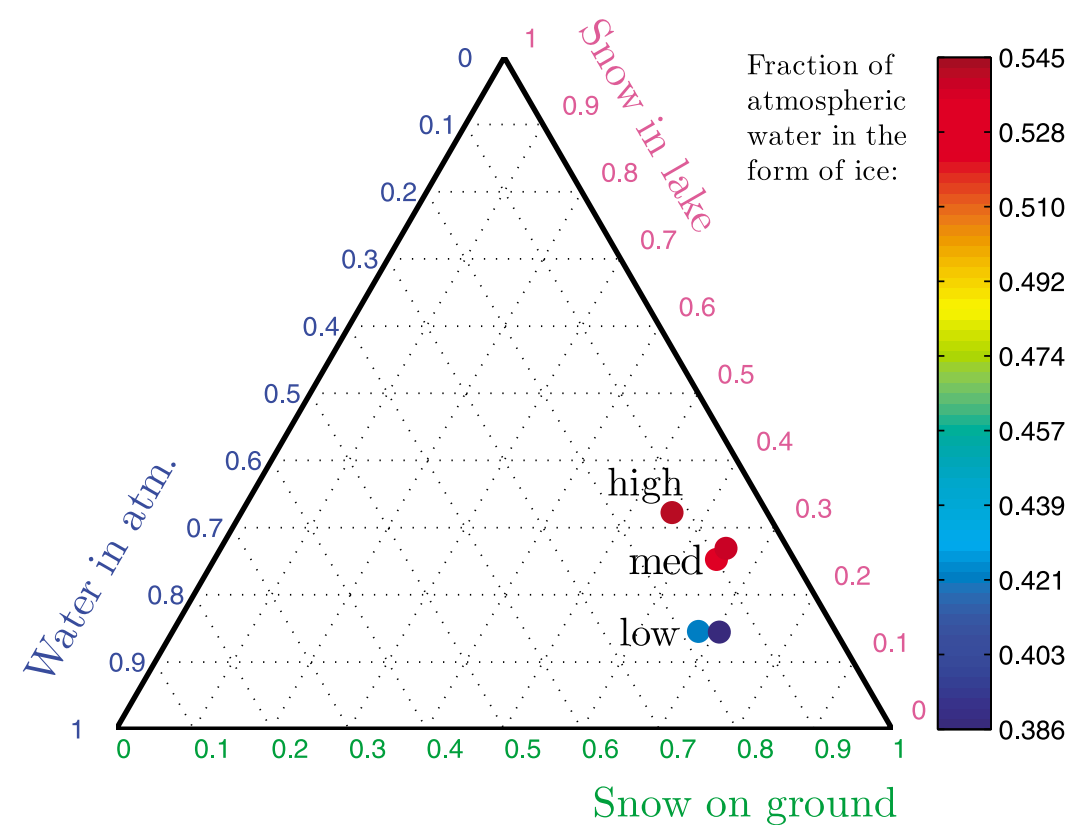

Figure 11. Fate of vapor released from the lake (precipitation efficiency). Colored dots correspond to the inventory of water (ice + vapor) after either 5 or 7 sols, after subtracting the inventory of a lake-free run. Color corresponds to fraction of atmospheric water in the ice phase: red is more ice-rich, blue is more vapor-rich. Only snow on ground can contribute to localized geomorphology. Water vapor in the atmosphere can contribute to regional and global climate change: global warming is increasingly likely as the mass of atmospheric water increases.

comparable because of the lower lake temperature in JUVENTAE_HIGH.

\section{Will Snow Melt?}

[30] We calculate the melting probability for snow precipitated from the storm using a 1D snowpack thermal model (Appendix C). This model is decoupled from the mesoscale model. We use the 1D model to assess all possible orbital states and solar luminosities. We show the likelihood that Mars' orbital state permits melting at the equator in Figure 12. The top panel excludes the greenhouse effect of the storm. The bottom panel includes this additional greenhouse effect. More recent times favor melting because of increasing solar luminosity. Higher pressures favor melting because of the suppression of evaporitic cooling and the greenhouse effect of added $\mathrm{CO}_{2}$.

[31] Our model will overestimate geomorphically effective snowmelt for two reasons. Parameters are chosen (Table 3) to favor melting: in particular, we use a dirty snow albedo of 0.28 , similar to Mars dust (Mellon et al. [2000] and discussed in Appendix C). Also, we do not include hydrologic effects. For example, if the porous layer is deeper than the diurnal thermal skin depth, melt percolating from the surface will refreeze. Such effects will limit the proportion of snowmelt available for runoff [e.g., Colbeck, 1976].

[32] Main results are as follows:

[33] 1. Boundary conditions for the mesoscale storm model are too cold for snowmelt under the faint young Sun. Snow is unlikely to melt at $12 \mathrm{mbar}$ (Figure 12). Some combination of the following is required to melt snow:- (1) higher atmospheric pressure; (2) non- $\mathrm{CO}_{2}$ greenhouse forcing; (3) a very large number of lake storms occurred, so that a few storm deposits encountered orbital conditions that allowed melt even though the probability of melting for each storm deposit was low; (4) transient warming from impact ejecta or a geothermal event; or (5) the deposits are younger than thought. We do not have enough information to choose between these. Absent direct warming from impact ejecta or a geothermal event, moderately higher pressures are almost certainly required (at least 50 mbar appears necessary). Strong evaporitic cooling suppresses melting at lower pressures. Transient warming from impact ejecta or a geothermal event could overcome evaporitic cooling, and it is possible that impacts or geothermal activity trigger chaos events [McKenzie and Nimmo, 1999; Wang et al., 2005]. Localized precipitation may not be possible at $50 \mathrm{mbar}$. Certainly the updraft vertical velocities will be reduced. In an idealized simulation at $60 \mathrm{mbar}$ (paper 1), precipitation was reduced by $20 \%$ relative to the 12 mbar case.

[34] 2. Snowmelt at low latitudes is more likely for snow that accumulates out of equilibrium with orbital forcing. More than half of the hottest orbital conditions occur at less than median obliquity (paper 1). Accumulation of annually persistent snow at the equator in equilibrium with orbital forcing is only possible for median obliquity or higher. Instantaneous emplacement from lake-effect storms can occur at any obliquity. Other factors (paper 1) also favor melting of localized storm deposits. We do not know the frequency of localized storms, so we cannot use this information to calculate the likelihood that an observed channel network formed from melting of instantaneously emplaced snow.

[35] We assume that storm deposits persist until the melt season. Is this reasonable? Low-latitude sublimation rates modeled by GCM [Madeleine et al., 2009] are $\sim 0.25 \mathrm{~m} / \mathrm{yr}$ w.e., with wide scatter. Given our modeled precipitation rates, lakes with lifetime $>10^{2} \mathrm{~h}$ generate snowpack this thick. 

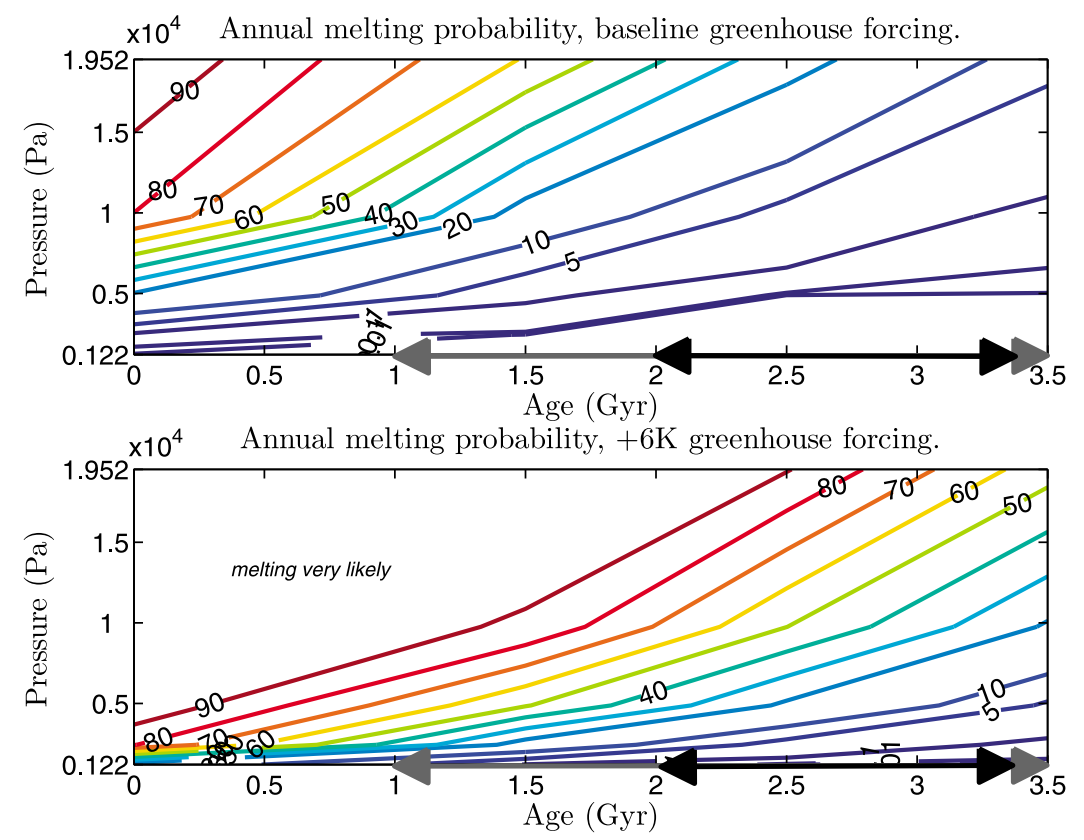

Figure 12. Equatorial melting probability (in \%) for flatlying snowpack. The four lowest probability contours correspond to $5 \%, 1 \%, 0.1 \%$, and $0.01 \%$. Gray arrow on the $\mathrm{x}$-axis corresponds to the range of possible ages for opaline layered deposits from Murchie et al. [2009a]. Black arrow corresponds to the smallest range of stratigraphic ages that could accommodate all the plateau channel networks according to Le Deit et al. [2010]. These ranges are large because of the uncertainties in mapping crater counts onto absolute ages [Hartmann, 2005], and it is possible that all the plateau channel networks formed at roughly the same time. Pressures on the y-axis range from $1220 \mathrm{~Pa}(\sim 2 \times$ present atmospheric level) to $19520 \mathrm{~Pa}(\sim 32 \times$ present atmospheric level). Our thermal model includes more terms than the model used by Kite et al. [2011], leading to slightly colder outcomes.

Table 3. Parameters Used in the Melting Model ${ }^{\mathrm{a}}$

\begin{tabular}{|c|c|c|c|}
\hline Symbol & Parameter & Value and Units & Notes/Reference \\
\hline$\phi$ & obliquity & $0^{\circ}-80^{\circ}$ & Laskar et al. [2004] \\
\hline$E$ & eccentricity & $0-0.16$ & Laskar et al. [2004] \\
\hline$L_{p}$ & longitude of perihelion & $0^{\circ}-180^{\circ}$ & symmetry at equator \\
\hline$L_{s}$ & season & $0^{\circ}-360^{\circ}$ & \\
\hline$P_{\text {atm }}$ & atmospheric pressure & $1220-19520 \mathrm{~Pa}$ & $2-32 \times$ present $\mathrm{CO}_{2}$ \\
\hline$\alpha$ & albedo of dusty snowpack & 0.28 & Very dusty snow \\
\hline$\tau$ & time of interest & $0-3.5$ Gyr ago & Mangold et al. [2004] \\
\hline$\sigma$ & Stefan-Boltzman constant & $5.67 \times 10^{-8} \mathrm{~J} \mathrm{~s}^{-1} \mathrm{~m}^{-2} \mathrm{~K}^{-4}$ & \\
\hline Sol length & duration of 1 Mars sol & $88775 \mathrm{~s}$ & \\
\hline$R_{\text {gas }}$ & gas constant & $8.3144 \mathrm{~J} /(\mathrm{mol} \mathrm{K})$ & \\
\hline$g_{\text {Mars }}$ & Mars surface gravity & $3.7 \mathrm{~m} / \mathrm{s}^{2}$ & \\
\hline$m_{c}$ & molar mass of $\mathrm{CO}_{2}$ & $0.044 \mathrm{~kg}$ & \\
\hline$m_{w}$ & molar mass of $\mathrm{H}_{2} \mathrm{O}$ & $0.018 \mathrm{~kg}$ & \\
\hline$M_{w}$ & molecular mass of $\mathrm{H}_{2} \mathrm{O}$ & $2.99 \times 10^{-26} \mathrm{~kg}$ & \\
\hline$\rho_{\text {now }}$ & density of atmosphere, present-day & $0.02 \mathrm{~kg} / \mathrm{m}^{3}$ & NSSDC \\
\hline$P_{\text {atm,now }}$ & pressure of atmosphere, present-day & $610 \mathrm{~Pa}$ & NSSDC \\
\hline$K_{\text {vonk }}$ & von Karman's constant & 0.4 & \\
\hline$z_{o}$ & roughness length & $0.1 \mathrm{~mm}$ & Polar snow/Brock et al. [2006] \\
\hline$z_{\text {anem }}$ & anemometer height & $5.53 \mathrm{~m}$ & E-MCD [Millour et al., 2008] \\
\hline$u_{\text {wind }}$ & reference near-surface wind speed & $3.37 \mathrm{~m} / \mathrm{s}$ & E-MCD (4 season "MY24" average) \\
\hline$r_{\text {humidity }}$ & relative humidity & 0.25 & \\
\hline$C_{p}$ & specific heat of Mars atmosphere & $770 \mathrm{~J} / \mathrm{kg} / \mathrm{K}$ & \\
\hline$k_{b}$ & Boltzmann's constant & $1.381 \times 10^{23} \mathrm{~m}^{2} \mathrm{~kg} \mathrm{~s}^{-2} \mathrm{~K}^{-1}$ & \\
\hline$L_{\text {subl }}$ & latent heat of sublimation & $2.83 \times 10^{6} \mathrm{~J} / \mathrm{kg}$ & \\
\hline$\epsilon$ & thermal emissivity of snow & 0.98 & \\
\hline$\rho$ & density of snowpack & $350 \mathrm{~kg} / \mathrm{m}^{3}$ & Carr and Head [2003] \\
\hline$C_{p}$ & Specific heat capacity of snow & $1751 \mathrm{~J} / \mathrm{kg} / \mathrm{K}$ & Carr and Head [2003] \\
\hline$k_{\text {snow }}$ & thermal conductivity of snowpack & $0.125 \mathrm{~W} / \mathrm{m} / \mathrm{K}$ & Carr and Head [2003] \\
\hline
\end{tabular}

${ }^{\mathrm{a} S e e}$ section 5 and Appendix C. 
Table 4. Measurements Relevant to Hydrology for Two Adjacent Inverted Channels ${ }^{\mathrm{a}}$

\begin{tabular}{lcc}
\hline & Catchment 1 & Catchment 2 \\
\hline$A$, area $\left(\mathrm{km}^{2}\right)$ & 1.6 & 2.1 \\
$w$, width $(\mathrm{m})$ & $3.3 \pm 0.8$ & $3.2 \pm 0.47$ \\
$S$, slope, $(\Delta z / \Delta x)$ & $0.82^{\circ}$ & $0.96^{\circ}$ \\
\hline
\end{tabular}

${ }^{\mathrm{a}}$ See Figure 15.

[36] Once liquid water is flowing, feedbacks can extend its lifetime. For example, in Greenland, supraglacial channels with water depth $>0.5 \mathrm{~m}$ reduce the albedo to close to that of water ( 0.05) [Lüthje et al., 2006]. Viscous dissipation can balance evaporative cooling of the stream only if

$$
S>\frac{e L}{\rho g u D}
$$

where $S$ is river slope, $e \sim 1 \mathrm{~mm} / \mathrm{h}$ is evaporation rate, $L$ is the latent heat of vaporization, $\rho=1000 \mathrm{~kg} / \mathrm{m}^{3}$ is density, $g$ is Mars gravity, $u=O(1) \mathrm{m} / \mathrm{s}$ is stream velocity, and $D=O$ (1) $\mathrm{m}$ is stream depth [Clow, 1994]. This condition is not satisfied for the Juventae plateau channel networks (which have slopes $<1 \%$; Table 4 ), so the stream will be roofed over by ice. Insulation of streams by ice can greatly extend liquid water lifetime [Clow, 1987].

\section{Channel and Layered Deposit Formation}

[37] We now evaluate formation mechanisms for the layered deposits and interbedded channel networks in light of our simulations. First we review constraints, including measurements from our own DTMs. We consider a series of options for the channel-forming mechanism, and test them against these constraints. These different mechanisms all assume that water is sourced from ephemeral lakes as in sections 2-5 (Figure 3, bottom). Next we drop the assumption that water is sourced from ephemeral lakes, and describe entirely different geological scenarios (Figure 3, top). We do not find decisive evidence that allows us to choose between these channel forming mechanisms or geological scenarios-we are left with multiple working hypotheses. We conclude by listing furture tests that could help decide among these multiple working hypotheses.

[38] In agreement with previous work [Mangold et al., 2008; Weitz et al., 2008], we interpret the networks of sinuous ridges and troughs to be fossil fluvial channels (Figure 13). Juventae plateau channels have low to moderate sinuosity. We have only found $2-3$ highly sinuous (meandering) channels. This should be compared to GaleAeolis-Zephyria, where most channels meander [Burr et al., 2009]. Most channels run down the present-day $0.2^{\circ} \mathrm{NNE}$ regional slope [Mangold et al., 2008]. Sinuous ridge width distribution appears bimodal. We suspect that the broader $O\left(10^{2} \mathrm{~m}\right)$ wide sinuous ridges are inverted valleys. Given that the channel networks are fossil fluvial channels, endmember channel-forming mechanisms are thermal erosion into ice, and mechanical erosion of sediment (Figure 3). These have corollary implications for the composition of the light-toned layered deposits: in the thermal erosion end-member case, the present-day plateau layered deposits must contain significant relict ice at depth. Relict water ice at the equator of Mars cannot be stable [Mellon and Jakosky,

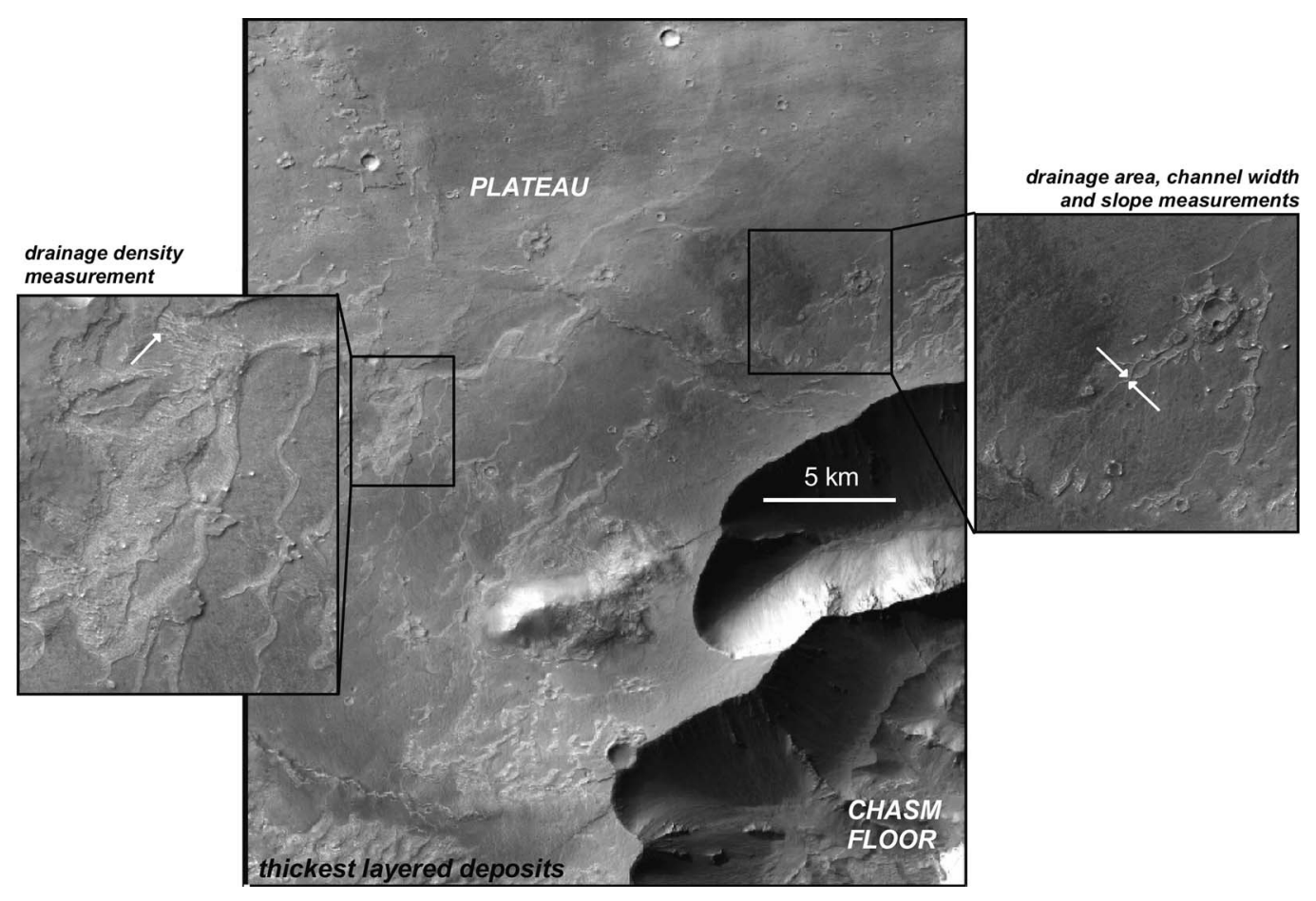

Figure 13. Geological context for measurements of layered deposit thickness, channel drainage density, catchment area, channel slope and channel width. White arrows in zoomed-in panels show localities. Background is part of CTX image P18_007983_1751_XN_04S063W. Some thickness measurements come from an area just SW of this image. 

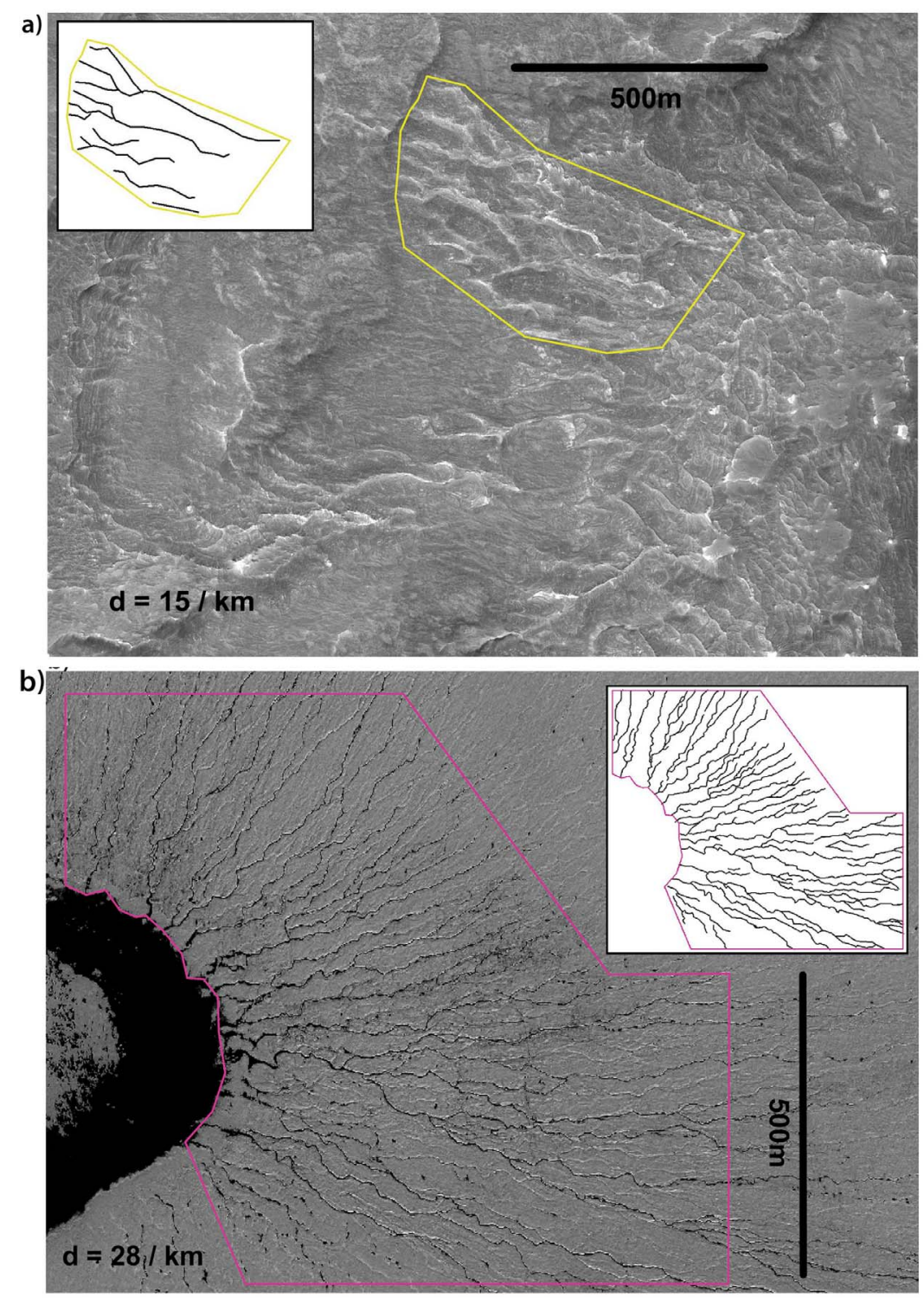

Figure 14. Comparison of the area of maximum drainage density at Juventae to snowmelt-carved systems on the Greenland ice plateau. Polygons enclose the area for which drainage density was measured, and the insets show channels which contributed to the count. (a) PSP_005346_1755, Juventae Plateau. This locality was identified by Malin et al. [2010, p. 38] as "the best evidence yet found on Mars to indicate that rainfall and surface runoff occurred." (b) IKONOS image of Greenland ice sheet, showing snowmelt-carved channels draining into a supraglacial lake. (Image courtesy J. Box, OSU/Discovery Channel; Box and Ski [2007].) Details: Greenland - length $=21.3 \mathrm{~km}$, area $=0.77 \mathrm{~km}^{2}$, giving drainage density $d=28 / \mathrm{km}$. Mars - length $=3.4 \mathrm{~km}$, area $=0.22 \mathrm{~km}$, giving drainage density $d=15 / \mathrm{km}$.

1995]. Geologic and radar evidence suggests that loss rates are sufficiently slow for ancient water ice to metastably persist in some equatorial locations [Head and Kreslavsky, 2004; Levy and Head, 2005; Shean et al., 2007; Watters et al., 2007; Mouginot et al., 2010; Warner et al., 2010; Shean, 2010; Lefort et al., 2011]. An example on Earth of the thermal erosion end-member case is the snowmelt-fed channel network that forms each summer on the Greenland ice sheet (Figure 14). In the mechanical erosion end-member case, the present-day plateau layered deposits are composed of (indurated) sediment grains.

\subsection{Implications of Constraints for Channel-Forming Mechanisms}

[39] Many of the channels are preserved in inverted relief. On Earth channels can become inverted through cementation of channel fill, armoring by coarse grains of the channel floor against erosion, or infilling of the channel by an erosionally resistant material such as lava [Williams et al., 2009]. Increased cementation of the channel thread, followed by differential erosion, is the most likely cause of inversion for inverted channels studied elsewhere on Mars [Williams et al., 2009; Burr et al., 2010]. Juventae's 
inverted channel networks lack evidence (such as pitting) for sublimation. They are often horizontally or subhorizontally layered, and the layers have variations in tone. They have well-defined, smooth, flat tops. These observations suggest that the inverted channels are composed of sediment and are not ice cored. Sediment fill is more consistent with the mechanical erosion end-member scenario than the thermal erosion end-member scenario.

[40] However, inverted channels on Mars do occur in icedominated, supraglacial and proglacial settings. Therefore, the interpretation that the inverted channels are composed of (indurated or cemented) sediment fill does not rule out thermal erosion of the progenitor channel. Midlatitude Amazonian glacier-associated channels at Lyot Crater (HiRISE image ESP_016339_2225) and Acheron Fossae (HiWish image ESP_018178_2165), and E of Reull Valles (HiWish image ESP_020055_1410) have become inverted [Fassett et al., 2010]. The Acheron inverted channel is $\leq 80 \mathrm{Ma}$ based on the age of its source glacier [Fassett et al., 2010]. In each case, glacier-associated channels appear to have incised into ice, but to have been incompletely filled with debris and sediment during or after incision. As surrounding ice retreats due to sublimation, the channel-filling sediment is left as a sinuous ridge.

[41] The layered deposits are tens of meters thick. We measure the present-day thickness of the plateau layered deposits close to the chasm edge as $43 \pm 11 \mathrm{~m}(n=13)$, using HiRISE DTMs. 33-39 layers are visible in HiRISE images of the thickest exposures (defining layers using laterally continuous changes in tone, slope or erosional morphology).

[42] In the thermal erosion end-member scenario in Figure 3, layered deposits are primarily water ice. The deposit thickness of $44 \pm 13 \mathrm{~m}$ then requires a minimum of 1400-2600 sols to accumulate at our peak precipitation of $0.9 \mathrm{~mm} / \mathrm{h}$, ignoring sublimation losses. Peak Maja discharge, $Q_{\text {maja }}=1.1 \times 10^{8} \mathrm{~m}^{3} \mathrm{~s}^{-1}$ [Kleinhans, 2005]. The volume of Juventae Chasma below the pour point is $\sim 7 \times$ $10^{4} \mathrm{~km}^{3}$ (ignoring the volume of Maja Valles itself). If this missing volume is $70 \%$ rock by volume and was exported over the spillway, with a fluvial sediment concentration of $1 \%$ by volume, the minimum cumulative time to carve Maja Valles is 740 sols. Peak discharge exceeds mean discharge, so Maja Valles operated for longer than this calculation suggests. In addition, an unfrozen lake may have remained in Juventae after the end of channel formation. Making the conservative assumption that there is only open water at the lake surface only when a catastrophic flood is occurring, the predicted deposit thickness is $28 \%-53 \%$ of the observed thickness. Because the Maja lifetime estimate is a lower limit, we do not think this discrepancy rules out the thermal erosion end-member scenario.

[43] The thickness of the deposits is also compatible with the mechanical erosion end-member scenario (Figure 3), in which the present-day plateau deposits are (indurated) sediments. Enough atmospherically transported material (sand, dust, and volcaniclastic material) must be brought in from other regions of a primarily dry Mars to account for observed thicknesses. Suppose atmospheric dust precipitable column abundance is $10 \mu \mathrm{m}$, background regional horizontal wind speed is $10 \mathrm{~m} / \mathrm{s}$, a circular storm region of radius $200 \mathrm{~km}$, and complete scavenging of dust by ice nuclei in the storm region. Then mass balance requires
1600-2700 years of cumulative storm activity to build up the observed thickness of plateau layered deposits (less if precipitation is concentrated). Alternatively, sediment could accumulate on the plateau between storm events as sand, dust or volcaniclastic materials, or be supplied from the chasm floor during the early stages of outflow events by buoyant plumes. Lake storms might be responsible for the channels in this case, but would not be the source of the material making up the layers. However, fluid released during snow melting could be responsible for the induration or cementation of these materials, and thus their long-term preservation (Figure 3).

[44] It is not possible for the layered deposits to entirely predate the channel-forming events because channels at different levels within the deposit crosscut each other.

[45] Drainage basin and channel dimensions and slopes permit relatively low runoff compatible with snowmelt. Even if the channels were cut by thermal erosion, some of them must have been infilled by sediment in order to form inverted channels (Figure 3).If the channels are formed in fine sediment by mechanical erosion, then sediment transport is required to form both the positive and the negative-relief channels. Therefore, in either end-member case, sediment must be transported through the observed channel network. The critical runoff $R$ needed to initiate sediment transport in a preexisting channel is [Perron et al., 2006]

$$
R_{c r i t}=\frac{1}{A} \frac{w^{2} \rho^{\prime} \tau_{c}^{*} D}{w S-2 \rho^{\prime} \tau_{c}^{*} D}\left(\frac{8 \rho^{\prime} g \tau_{c}^{*} D}{f}\right)^{\frac{1}{2}}
$$

where $R_{\text {crit }}$ is the critical runoff rate, $A$ is drainage area, $w$ is channel width, $\rho^{\prime}=\left(\rho_{s} / \rho_{f}\right)-1$ is the normalized density, $\rho_{s}$ is sediment density, $\rho_{f}$ is fluid density, $\tau_{c}^{*} \approx 0.05$ is the critical Shields number, $D$ is sediment grain diameter, $S$ is slope, $g$ is Mars gravity, $f$ is the Darcy-Weisbach friction factor, and all units are mks. We assume basaltic sediment $\rho_{s}=3000 \mathrm{~kg} /$ $\mathrm{m}^{3}$ and water density $\rho_{f}=1000 \mathrm{~kg} / \mathrm{m}^{3}$. In alluvial streams, $f$ is closely related to grain size, but no similar relationship has been published for thermally eroded channels. $A, w$, and $S$ are taken from our DTMs, as shown in Figure 15, tabulated in Table 4, and described below.

[46] Area measurements were made as follows. Erosion has scoured the deposits between preserved inverted channels, removing the drainage basins that once sourced those channels. We therefore divide the area between channels by equidistance. Because there have been multiple episodes of crosscutting flow, some truncation of channels by subsequent generations of channel may have occurred, which may lead to a systematic underestimate of $A$ and corresponding overestimate of $R_{\text {crit }}$.

[47] Width measurements were made as follows. We measure channel widths using the distinctive, light-toned region at the top of the sinuous ridges visible in HiRISE images. DTMs confirm that this light-toned strip forms the summit of the much broader ridge, and often resolve a break-in slope near the top of the ridge approximately corresponding to the light-toned strip in the red-filter HiRISE images. This is frequently much narrower than the total ridge width visible in shaded-relief DTM images such as Figure 15. By analogy with inverted channels near Green River, Utah [Williams et al., 2007], these observations suggest that the bright region whose width we are measuring 


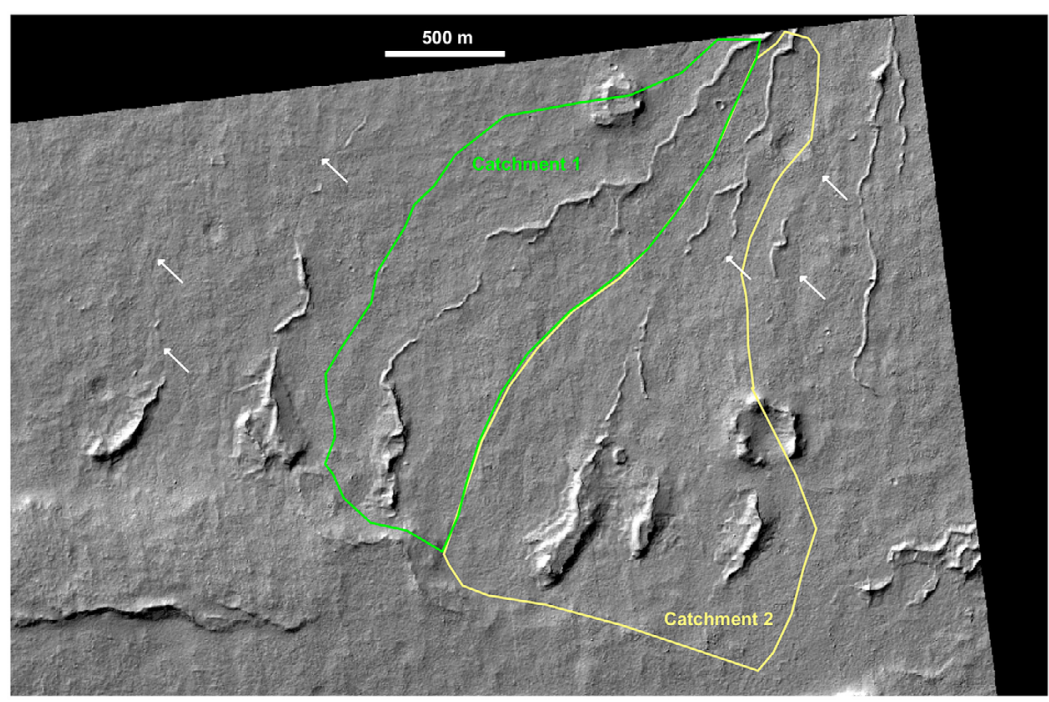

Figure 15. Inverted channel systems on the Juventae plateau from which hydraulic parameters were measured. Shaded relief from HiRISE stereo DTM 1 (Figure 4), illuminated from top left. North is up. Streams flow down present-day slope. Barely visible striping parallel to the edge of the shaded relief raster is an artifact of stereo DTM generation. Inverted channel heights are typically $2-5 \mathrm{~m}$. Shallow negative-relief channels (white arrows, depth $<1 \mathrm{~m}$ from DTM) join some inverted channel segments. The corresponding HiRISE image pair is PSP_003223_1755 and PSP_003724_1755.

corresponds to an erosionally resistant and vertically thin channel-fill deposit capping underlying weaker material. The channel widths we obtain are several meters for drainage areas $O(1) \mathrm{km}^{2}$ (Table 4). These widths may correspond to indurated channel fill (or valley fill) sediments that are wider than was the instantaneous channel. (Much wider ridges are seen elsewhere, but these are the largest channels for which we have area and DTM slope constraints.)

[48] Slope measurements were made as follows. We take an average slope along the exposed length of the channel. There is no visually obvious evidence of major postdepositional tilting of the plateau - the channels run approximately down the present-day slope.

[49] $R_{\text {crit }}$ for a catchment of area $1.6 \mathrm{~km}^{2}$ and slope $0.8^{\circ}$ feeding a channel of width $3.3 \mathrm{~m}$ is shown in Figure 16. The adjacent catchment of area $2.1 \mathrm{~km}^{2}$ produces almost indistinguishable results. Both networks are from DTM1 (Appendix D). We assume runoff $R \approx M$, where $M$ is the melt rate. $R$ will only approach this upper bound if there is a shallow impermeable ice table, or if the substrate is covered with fine-grained material that has a low infiltration rate. An upper limit on $M$ is if all precipitation melts upon reaching the ground. Then the resulting runoff can mobilize coarse gravel (thick black line in Figure 16). However, a more realistic melt rate is $0.1 \mathrm{~mm} / \mathrm{h}$. This is still capable of initiating the transport of coarse sand and fine gravel through the network (lower bound of gray envelope in Figure 16). The upper limit on the gray envelope in is an order-of-magnitude error intended to capture errors in the precipitation model, weather, and especially the width and area measurements discussed above. We conclude from the area covered by this gray envelope that if boulder-sized ( $>256 \mathrm{~mm}$ diameter) clasts have been transported through these channel networks, that would be strong evidence against localized precipitation. Howard et al. [2007] provide criteria for distinguishing

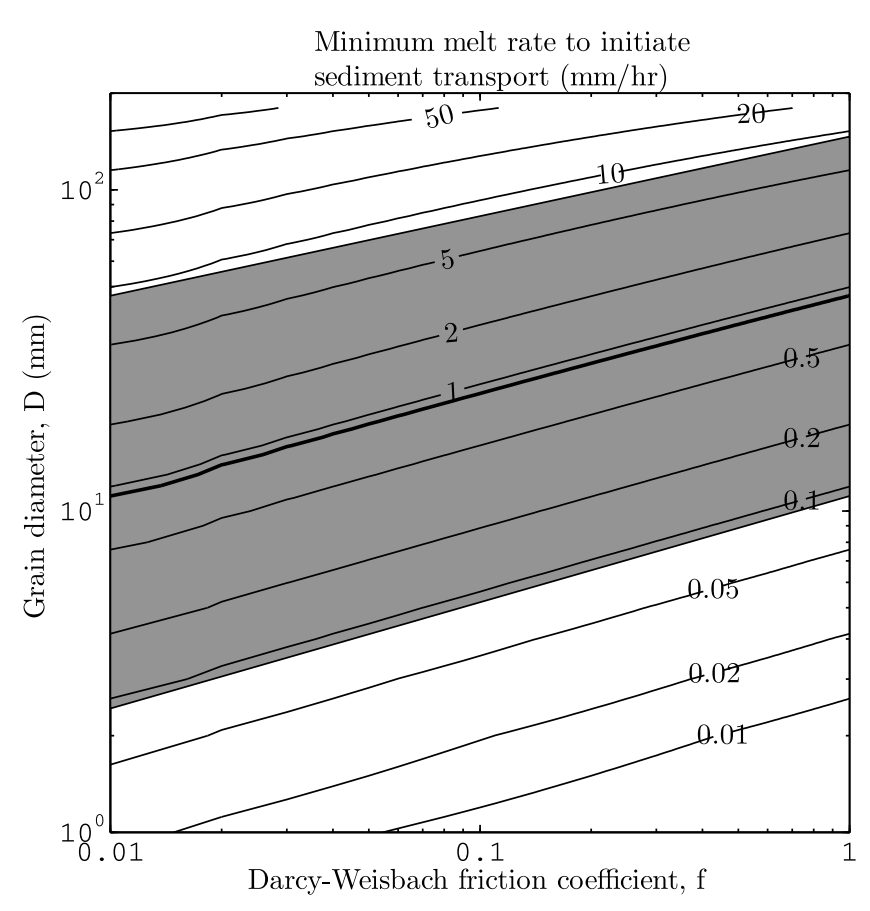

Figure 16. Grain sizes that can be mobilized by the modeled precipitation. The central black line corresponds to the modeled snowfall rate, $0.9 \mathrm{~mm} / \mathrm{h}$. Because the modeled precipitation rate is only an order-of-magnitude guide to the true precipitation rate, the gray envelope shows orderof-magnitude uncertainties in both directions. The melting rate will be lower than the precipitation rate, and in our probabilistic discharge model the exceedance probability for a melt rate of $1.0 \mathrm{~mm} / \mathrm{h}$ is extremely low. Melt rates of $0.09 \mathrm{~mm} / \mathrm{h}$ (lower end of gray envelope) are more likely. Even these are sufficient to mobilize sand and gravel. 
fluvially transported boulders from postdepositionally cemented blocks. Any clast that can be resolved by HiRISE is a boulder.

\subsection{Alternative Interpretations and Tests}

[50] In section 2, we infer that location adjacent to a chasm supplies one or more limiting factors for inverted channel formation. Likely limiting factors included availability of snow or rain, sufficient heat for melting, availability of sediments that can be mobilized, cementing fluids, and incomplete erosion. In sections 3-5, we develop and test the hypothesis that precipitation is limiting. Results are consistent with the hypothesis. What about heat, sediment, cementing fluids, and erosion? Can we rule any or all out?

[51] Precipitation on the Valles Marineris plateau sourced from ephemeral chaos lakes is one model compatible with data, but other scenarios are also possible (Figure 3, top). For example, we cannot currently rule out a scenario where the observed narrow, extended Valles Marineris cloud trails $(0.4 \mu \mathrm{m}$ effective diameter [Clancy et al., 2009]) increase spectacularly in mean grain size and move closer to the canyon edge during different orbital conditions or dust loading, permitting regional precipitation. Near-surface waterice morning fog occurs in Valles Marineris today [Möhlmann et al., 2009], and OMEGA has detected surface water ice on the northern wall of Coprates Chasma [Vincendon et al., 2010]. Net annual ice accumulation within the Valles Marineris occurs in GCMs at high and moderate obliquity [Madeleine et al., 2009], although this is largely due to the high thermal inertia of the chasm walls (J. B. Madeleine, via email). Taken together, this evidence suggests that Valles Marineris is a preferred site for equatorial ice precipitation, which is important at high obliquity [Jakosky and Carr, 1985; Jakosky et al., 1995; Mischna et al., 2003; Forget et al., 2006]. In this high-obliquity precipitation scenario, snowpack is broadly distributed in the Valles Marineris region, but generally does not melt. This possibility is discussed by Le Deit et al. [2010]. The limiting factor provided by the chaos regions is then airborne darkening agents (ash and/or debris) sourced from the chasm floor and lofted by buoyant plumes ("dirty thunderstorms" [van Eaton et al., 2010]), which lead to patchy melting or patchy preservation of a broadly distributed, preexisting snowpack. Alternatively, ash and/or debris forms a cast of the channels, which form over a broad region but disappear elsewhere when the snowpack sublimes. A weakness of this scenario is that both the observed fog and surface ice, and the predicted high-obliquity net ice accumulation, are on the chasm floor and walls and not to the adjacent plateau. Opal-bearing layered deposits and channel networks are overwhelmingly found on the plateau, not the floor and walls (Figure 2). Another weakness is that no geomorphic evidence for explosive volcanism has been found on the floor of Juventae Chasma.

[52] Another alternative source of water is springs. Before chasm opening had begun, drainage from aufeis blisters, or groundwater, could source springs [Gaidos and Marion, 2003; Murchie et al., 2009b]. In this scenario, the layers and channel networks predate outflow channel formation. This would not explain the downwind preference for channel networks, but there is a $7 \%$ possibility that this could be due to chance (section 4, Figure B1).
[53] Among these three scenarios (Figure 3), our preference for the chaos lakes model is tentative, but testable. First, a more complete study of the plateau channel networks, using HiRISE DTMs where possible, and using channel width as a proxy for discharge [Montgomery and Gran, 2001, and references therein], would test the spring hypothesis and the precipitation hypotheses. If plateau channels were fed by a small number of point or line sources, channel widths should be constant between confluences (and channel sources should correlate to linear fractures, shear bands, or mineralogical anomalies). If precipitation or distributed groundwater flow fed the channels, channel widths should increase with contributing area as seen on Earth, and channel sources should not be correlated with fractures or mineralogical anomalies. Second, further tests of the localized-precipitation model at other sites might uncover inconsistencies that would weaken the model's application at all sites including Juventae. Possible sites include Echus, Ganges, Cerberus Fossae and Mangala Fossae. We report initial results from one such test (at Echus) in section 7.

[54] Additional predictions are specific to the thermalerosion end-member scenario (Figure 3): failure of these predictions would not rule out the mechanical-erosion endmember scenario (Figure 3). The thickness of the layered deposits should decrease away from the chasm edge in proportion to the mean precipitation rates predicted by localized precipitation models (e.g., Figure 9). Finally, SHARAD observations can test if the light-toned layered deposits have a vertically averaged dielectric constant consistent with relict ice, as is required by the thermal-erosion end-member scenario.

\section{Echus Plateau}

[55] The greatest of the outflow channels is Kasei Valles [Williams et al., 2000]. Kasei's source is lava-floored Echus Chasma. Beyond the $5 \mathrm{~km}$-high chasm wall, on the Hesperian plateau, dendritic channel networks are abundant (Figure 17a) [Chapman et al., 2010a, 2010b; Mangold et al., 2004, 2008]. The floor of Echus Chasma is now $200 \mathrm{~m}$ below a saddle that marks the start of the main channel. Regional topography suggests that the floor of Echus was once much deeper [Harrison and Chapman, 2008].

[56] Although no opal or hydroxylated sulfates have been reported on the Echus plateau [Milliken et al., 2008], the erosional properties of the substrate for the Echus channel networks resembles the erosional properties of the Juventae plateau layered deposits. Material on the SE rim of Echus is relatively thinly layered, relatively light-toned in outcrop, and recessed from the chasm edge, suggesting a sedimentary or volcaniclastic origin (CTX image P14_006586_1800_XN_00N079W). It is cut by very broad valleys, which bottom out on more resistant basalt, suggesting it is less resistant to fluvial erosion (P02_001839_1806_XN_00N079W).

[57] Our simulations of the Echus plateau channel networks, which are preserved in negative relief, show peak non-lake precipitation in the densest area of observed channels, at $0.7 \mathrm{~mm} / \mathrm{h}$ (Figure 17a). Because of the interaction of lake convergence, topography, and the regional windfield, precipitation is also predicted $\mathrm{S}$ and $\mathrm{E}$ of the chasm beyond the existing mapped area of channels. 

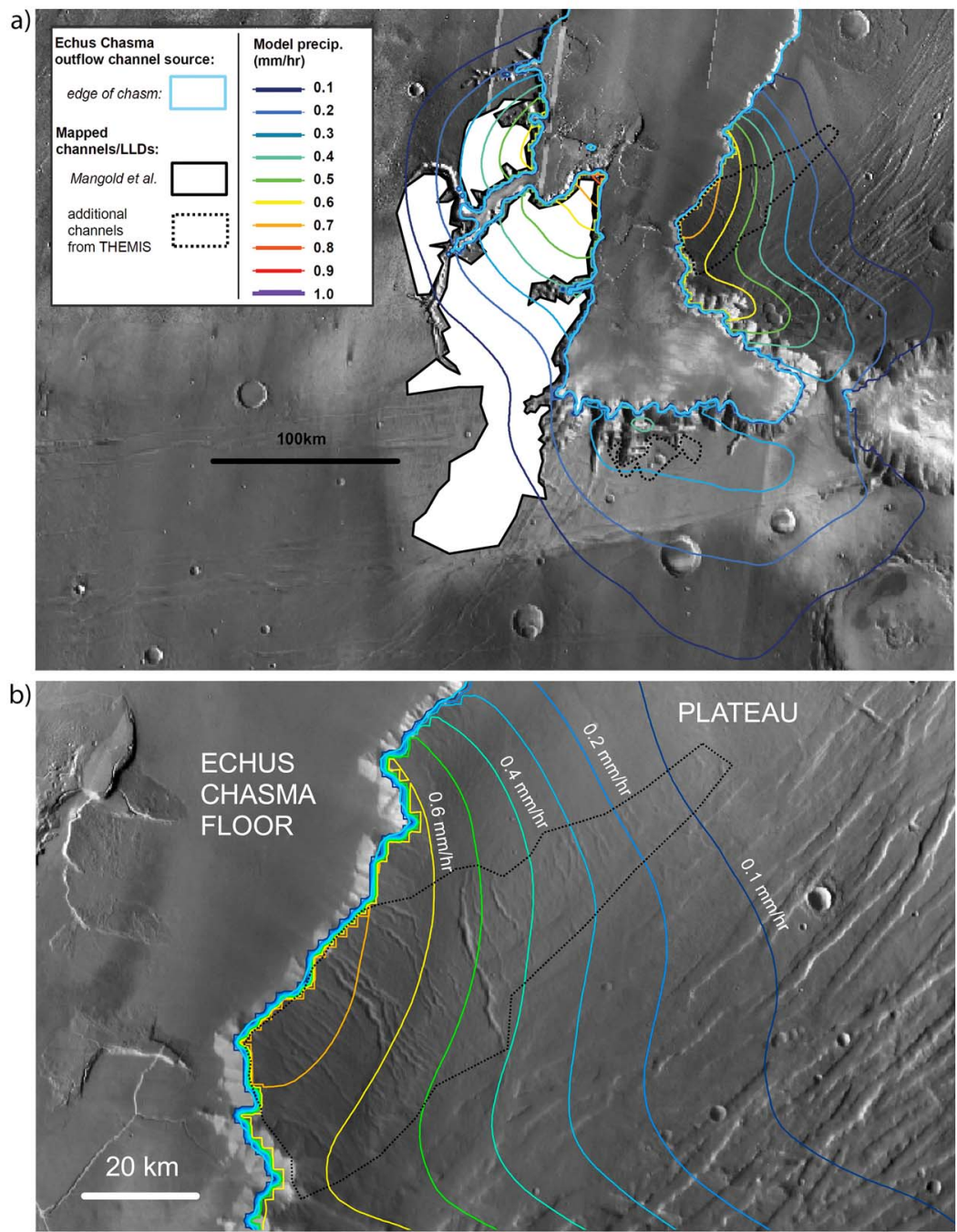

Figure 17. (a) Modeled precipitation contours overlain on observed geology at Echus. White shading with thick solid black outline is the perimeter of channels reported by Mangold et al. [2004]. The dotted black line corresponds to additional channels observed in the THEMIS Day IR $100 \mathrm{~m}$ per pixel global mosaic. The colored lines are modeled mean precipitation contours at intervals of $0.1 \mathrm{~mm} / \mathrm{h}$ water equivalent. Precipitation falling into the lake is not shown. (b) Focus on area where channels have not been previously mapped. The dotted line encloses the area of channels visible in THEMIS IR mosaic. The depth and width of the observed channels decrease away from the chasm edge in step with the decline in modeled precipitation.

THEMIS and CTX show extensive channelization in these areas (dotted lines in Figure 17a), which die away on a length scale similar to the length scale of predicted precipitation (Figure 17b). Cursory inspection of CTX images further away from the channel edge does not show channelization. These results are consistent with localized precipitation. Incomplete geomorphic mapping of the Echus headwaters currently prevents more thorough hypothesis testing, but this is a promising initial result that suggests our ability to match observations at Juventae with only localized precipitation can be reproduced elsewhere.

[58] The Echus plateau channel networks are deep and extensive compared to the Juventae plateau channel networks. It is not clear whether the cumulative duration of outflow channel activity within Echus Chasma would deposit enough water to produce the Echus plateau channel networks. Chapman et al. [2010b] gives $82 \mathrm{~km}^{3}$ total erosion over an eroded outcrop of $\sim 30000 \mathrm{~km}^{2}$, corresponding to an average of $2.7 \mathrm{~m}$ material removed. With a melt season length of 30 sols, melting of $1 \mathrm{~mm} /$ day, and a fluvial sediment:water ratio of 100:1, 9000 years would be required to cut the observed channels.

[59] We predict that future simulations of lake-effect storms in Ganges Chasma should produce precipitation that is concentrated near the Ganges plateau inverted channels. However, not every post-Noachian paleolake on Mars has associated inverted channel networks [Mangold and Ansan, 2006; Dehouck et al., 2010]. Possible limiting factors include low atmospheric pressure (section 5, Figure 12), a lack of mobilizeable sediment (section 2), or a lack or cur- 
rents, bubbles or wind to mix the lake and prevent rapid freezing over of the lake's surface (section 4.1).

\section{Implications for Regional and Global Climate Change}

[60] Most water vapor released in our simulations is trapped by localized precipitation near the lake, and so is unavailable for broader climate change (Figure 11). Remaining atmospheric vapor load is less than present-day global loads [Smith, 2002], and we do not expect a global excursion to wet conditions (the MEGAOUTFLO hypothesis [Baker et al., 1991; Baker, 2001; Quantin et al., 2005]) to result from water vapor release during chaos events (Figure 11). There are four caveats: (1) Simultaneous triggering of chaos events in multiple chasms, or the broad area of outwash at the terminus of the outflow channels, would provide a larger interface for water vapor injection to the atmosphere than is simulated here. Supposing an evaporation rate of $2 \mathrm{~mm} / \mathrm{h}$, for $5 \%$ global water cover, and in the absence of precipitation, the atmosphere will contain 6 mbar water in 70 sols. Water vapor is a powerful greenhouse gas and 6 mbar of water vapor would cause noticeable global warming. But precipitation will occur, and it is likely that outwash freezes over in $\ll 70$ sols. Inner channels within the outflow channels indicate that the outflow channels were incised by much lower discharge rates than previously thought [Williams et al., 2000]. This does not support the hypothesis of large Late Hesperian and Amazonian seas: at low discharges, water would freeze and perhaps sublime, redepositing at planetary cold traps. (2) Noncondensible gases such as $\mathrm{CO}_{2}$ or $\mathrm{CH}_{4}$, stored in cryosphere clathrates (or deep aquifers) and outgassed during chaos events [Bargery and Wilson, 2010], could provide warming. (3) If chaos events are triggered by magma bodies laden with $\mathrm{CO}_{2}, \mathrm{SO}_{2}$, and halogens, then chaos events and transient greenhouse warming could occur simultaneously [e.g., Johnson et al., 2008]. (4) If atmospheric pressure was much higher (e.g., hundreds of mbar) this would suppress the buoyant instability that leads to localized precipitation, allowing more water vapor to escape to the background atmosphere (paper 1).

[61] Our model indicates that regional or global temperatures warmer than today are not required to explain snowmelt at the location of the outflow-channel associated valley networks (section 5, Appendix C, Figure 12). However, the present atmospheric state is incapable of allowing melt under the Faint Young Sun $\sim 3.0$ Ga when the channels formed (Figure 12). Channel formation requires either a change in background atmospheric state, or transient heating from impact ejecta or geothermal activity. If transient heating did not occur, then atmospheric pressure $>50 \mathrm{mbar}$, non- $\mathrm{CO}_{2}$ greenhouse forcing, or both, are very likely required to raise the melting probability.

[62] If melting probability $<1$ during plateau layered deposit deposition, why are channels found throughout the stratigraphic column? We suggest three possible explanations. (1) Melting is needed to produce water that indurates the sediment. Since induration increases resistance to aeolian erosion, the stratigraphic record on the Juventae plains is a wet pass filter. It is biased toward preservation of the chaos storm deposits that were accompanied by melting. (2) Runoff accompanied only a few layer-forming events, but the chan- nels cut from the top to the bottom of the sedimentary stack. Meltwater percolated through the stack and cemented all layers. Deeply incising, rather than superficial, channels are suggested by the observation of negative-relief channel continuous with channel-topped ridges (Figure 15). If the 33-39 layers identifiable in the stratigraphic column correspond to 33-39 lake events, and modeling melt events as a Poisson process, the probability of melting occurring on the plateau at some point in the year following at least one chaos event is $49 \%-54 \%$ for a melting probability of $2 \%$. (3) The chaos events were correlated with orbital conditions, with chaos events preferentially occurring during times that favored melt.

[63] Movement of the melt pulse through the watershed is not considered here. However, discharge of $<0.05 \mathrm{~m}^{3} / \mathrm{s}$ is sufficient to move fine sediment through the $\mathrm{km}$-scale drainage networks visible in our DTM (Figure 15). With DTM drainage network and channel geometries, runoff of $0.1 \mathrm{~mm} / \mathrm{h}$ is approximately the required runoff for mobilization of fine gravel/granules, and runoff of $1.0 \mathrm{~mm} / \mathrm{h}$ will mobilize medium gravel (Figure 16).

[64] The dendritic channels provide strong evidence for water runoff and are prima facie evidence that global temperatures and pressures permitting surface liquid water runoff persisted (or were revived) well after the Late Noachian/ Early Hesperian maximum in valley network formation. However, our observations and models are consistent with a transient and localized response to disequilibrium forcing from catastrophic groundwater release-weather, not climate [Kite et al., 2011].

\section{Conclusions}

[65] We make the following conclusions:

[66] 1. In mesoscale simulations of lake storms during chaos formation at Juventae Chasma, peak precipitation over land occurs to the SW of the chasm. This corresponds to the location of the observed Juventae plateau channel networks. The location is sensitive to lake surface elevation.

[67] 2. Peak snowfall of $1.7 \mathrm{~mm} / \mathrm{h}$ water equivalent (w.e.) and mean snowfall of $0.9 \mathrm{~mm} / \mathrm{h}$ w.e. occurs at the location of the observed plateau channel networks. These rates are sensitive to lake surface elevation and lake temperature.

[68] 3. Mesoscale model output is consistent with a contribution from material lofted from Juventae Chasma (and transported $\mathrm{W}$ by the background wind field) to channel formation on the Juventae plateau.

[69] 4. The minimum background atmospheric temperature to allow melting of localized snowstorm deposits is sensitive to snowpack albedo, solar luminosity, atmospheric pressure and orbital conditions. Melting is impossible under the Faint Young Sun with today's atmospheric composition. Higher atmospheric pressure, and a modest non- $\mathrm{CO}_{2}$ greenhouse contribution, are probably both required for melting under the Faint Young Sun.

[70] 5. Juventae's plateau channel networks could have formed from localized precipitation, and do not require global warm/wet conditions.

[71] 6. The majority of water vapor released to the atmosphere during chaos flooding is trapped by localized precipitation at the chasm edge, and is not available to drive global climate change. 
[72] 7. This model is not unique. Alternative explanations of channel formation that are compatible with stratigraphic constraints include patchy melting of broadly distributed equatorial snowpack, and spring discharge of groundwater on the plateau early in the formation of Juventae Chasma.

[73] 8. Our model strongly predicts that plateau channel networks will not be found $>250 \mathrm{~km}$ from a surface water vapor source. It also predicts that additional plateau channel networks and plateau layered deposits should be identified downwind of large, localized vapor sources elsewhere on Mars.

\section{Appendix A: Mesoscale Model}

[74] The fully compressible dynamical core of MRAMS is derived from the terrestrial RAMS code [Pielke et al., 1992] that has been adapted to Mars, by S. C. R. Rafkin and others [Rafkin et al., 2001]. Dust and cloud microphysics based on the Community Aerosol and Radiation Model for Atmospheres (CARMA) [Toon et al., 1988] have been added to MRAMS, and we made use of these capabilities in our Juventae study.

[75] Only the microphysics and vertical sedimentation components of CARMA have been retained [Michaels et al., 2006]. In the MRAMS implementation used here, there are eight microphysical dust mass bins. The first dust mass bin corresponds to a particle radius of $0.05 \mu \mathrm{m}$, with the mass of each successive bin increasing by a factor of 7.2. The initial atmospheric dust loading used by the cloud microphysics is taken from the GCM, and it is not replenished in any way throughout the MRAMS run. The initial dust number distribution is $\log$ normal with a mean radius of $1.5 \mu \mathrm{m}$, and a geometric standard deviation of 1.8. Dust serves as water ice nuclei, and as such is scavenged during cloud formation. In addition to microphysically active dust, there is a static background dust loading that is only used to maintain nominal Mars dust opacity for the radiative transfer (RT) calculation. This background dust is based on MGS TES column dust opacity [Smith, 2004]. Both the background dust and the microphysically active dust are radiatively active.

[76] Water ice microphysics are implemented using 18 mass bins (first mass bin corresponds to a particle radius of $0.072 \mu \mathrm{m}$ ), with the mass of each successive bin increasing by a factor of 7.2. The contact parameter for nucleation is 0.95 . Microphysical dust and water ice particles are advected, gravitationally sedimented, and diffused in the model. The background dust is not altered in any way by any simulated physical process.

[77] Atmospheric boundary and initial conditions, including dust and water vapor, are taken from the NASA Ames Mars GCM (MGCM) [Haberle et al., 1993] driven by present-day orbital parameters. The MGCM includes an active water cycle based on the microphysical scheme of Colaprete et al. [1999] and is tuned appropriately to match the MGS-TES observed column water vapor and cloud ice abundance [Smith, 2004]. Any water ice in the GCM is added to the GCM water vapor field, and this total water substance field is used by MRAMS. The mass of dust serving as nucleation cores for any GCM water ice aerosol is returned to the total GCM dust field and then used by MRAMS. Unlike the dry Martian climate which spins up rapidly within the MGCM, the water cycle requires several years or more of simulation to achieve stability. Therefore, data from the sixth Mars-year of the MGCM simulation is used.

[78] The water ice and total dust (background plus microphysically active) are treated as being radiatively active, using a two-stream radiative transfer algorithm based on the work by Toon et al. [1989]. The optical parameters for these aerosol particles were calculated with a Mie theory code. Aerosol particles were assumed to be spherical, and wavelength-dependent refractive indices were taken from measurements of water ice and Hawaiian palagonite.

[79] Vertical resolution varied from $2.3 \mathrm{~km}$ at the top of the model to $30 \mathrm{~m}$ near the ground. We used four grids with the outermost being hemispheric and a horizontal resolution of $\sim 8.9 \mathrm{~km}$ on the inmost grid. Output was sampled every $1 / 24$ sol $(\approx 3699$ s), or "Mars hour." We assume that this frequency, limited by available disk space, is enough to capture model behavior-for example, we refer to the warmest of 24 samples during a sol as the "day's maximum temperature." The time step varied between runs but was never more than $3.75 \mathrm{~s}$ on the inmost grid.

\section{Appendix B: Comparison Between Area of Modeled Precipitation and Area of Observed Channels}

[80] Because (1) channels are exposed by incomplete erosion of the plateau layered deposits, (2) the inverted channels are themselves layered, and (3) channels are found wherever layered deposits are incompletely eroded on the Juventae plateau, we assume that areas containing lighttoned layered deposits also contain channels.

[81] We compared model predictions to geologic data in four ways:

[82] First, we use the method of Pielke and Mahrer [1978]. Following Pielke [2002], let $A_{4}$ be the area of the inmost grid in the MRAMS domain, $P_{i, t}$ be the area of precipitation predicted by meteorological model $i$ above some threshold value $t$, and $G_{j}$ be the area of channels and light-toned layered deposits (collectively referred to as "geology," for brevity) mapped using criteria $j$. Then the skill of the model in predicting geology is

$$
\text { skill }=\frac{F_{E}}{F_{M}}=\frac{\left(P_{i, t} \cap G_{j}\right) / G_{j}}{P_{i, t} / A_{4}}
$$

where $F_{E}$ is the fraction of the geology in areas with model precipitation above the threshold, and $F_{M}$ is the fraction of the model domain over which the model precipitation is above the threshold. The fraction of the model-predicted area that is occupied by geology, or coverage

$$
\text { coverage }=\left(P_{i, t} \cap G_{j}\right) / P_{i, t}
$$

is a measure of the tendency of the model to overpredict the observed geology (where a value of 1 corresponds to no overprediction). Here, the null hypothesis is that the association between model and data is due to chance. skill and coverage are shown in Table 5. JUVENTAE_HIGH shows the greatest skill, for both $j$. We obtain skill values $>200$ for JUVENTAE_HIGH and $t=0.8 \mathrm{~mm} / \mathrm{h}$. For these cases, the area of overlap between prediction and data is $>200$ times 
Table 5. Model Skill Using Method of Pielke and Mahrer [1978]

\begin{tabular}{|c|c|c|c|c|c|c|c|c|c|c|}
\hline & \multicolumn{10}{|c|}{ Precipitation $(\mathrm{mm} / \mathrm{h})$} \\
\hline & \multicolumn{7}{|c|}{ Skill } & \multicolumn{3}{|c|}{ Coverage } \\
\hline & 0.02 & 0.2 & 0.4 & 0.6 & 0.8 & 0.02 & 0.2 & 0.4 & 0.6 & 0.8 \\
\hline \multirow[t]{2}{*}{ JUVENTAE_LOW } & 11 & 0 & 0 & 0 & 0 & 0.040 & 0 & 0 & 0 & 0 \\
\hline & 11 & 0 & 0 & 0 & 0 & 0.009 & 0 & 0 & 0 & 0 \\
\hline \multirow[t]{2}{*}{ JUVENTAE_MED } & 5 & 19 & 50 & 108 & 122 & 0.020 & 0.071 & 0.185 & 0.403 & 0.455 \\
\hline & 5 & 19 & 51 & 138 & 227 & 0.004 & 0.015 & 0.041 & 0.111 & 0.182 \\
\hline \multirow[t]{2}{*}{ JUVENTAE_HIGH } & 6 & 33 & 120 & 229 & 269 & 0.022 & 0.122 & 0.446 & 0.853 & 1.000 \\
\hline & 6 & 33 & 136 & 293 & 498 & 0.005 & 0.026 & 0.109 & 0.235 & 0.400 \\
\hline
\end{tabular}

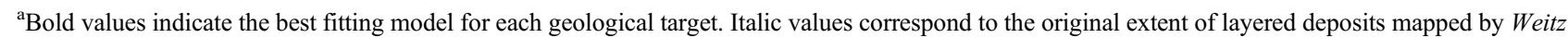
et al. [2010], and normal text is the value for Le Deit et al. [2010]. The $1.0 \mathrm{~mm} / \mathrm{h}$ is not shown because there is only 1 pixel with this value.

greater than expected by chance, showing that the agreement is almost certainly not due to chance.

[83] Second, we use a Monte Carlo method. For this metric, we determine the fraction of randomly placed precipitation templates that provide a better fit to the geologic observations than the modeled precipitation. We take the predicted precipitation $P$ for each model $i$, including snow falling back into the lake (the precipitation "template"), and randomly translate it in latitude and longitude, wrapping around the boundaries of the inmost model grid $(\sim 1300 \mathrm{~km} \times$ $\sim 870 \mathrm{~km}$ ). This creates a new modeled precipitation grid $Q_{i}$. A data grid $G_{j}$ is constructed by assigning 1 to areas containing mapped inverted channels or light-toned layered deposits and 0 otherwise. We then calculate the cross-correlation as

$$
X=G_{j}^{\prime} * Q_{i}^{\prime}
$$

where the primes denote normalization (for each trial) by subtracting the nonlake mean and dividing by the nonlake standard deviation. The area of the lake (which is not translated) is masked out in all cases. We repeat this $10^{4}$ times. Here, the null hypothesis is that the geology formed from a localized source of some kind, but that the location of this source was uncorrelated with present-day Juventae Chasma. The resulting $\mathrm{p}$-values are 0.005 for JUVENTAE HIGH (nominal $X=0.476$ ), 0.009 for JUVENTAE MED (nominal $X=0.365$ ), and 0.058 for JUVENTAE $\bar{L}$ LW (nominal $X=0.044)$. These are for the map of Le Deit et al. [2010]. The null hypothesis is rejected at the $99.5 \%$ level for JUVENTAE HIGH: if the observed channels and layered deposits formed from a localized source of some kind, it was almost certainly close to the present-day center of Juventae Chasma.

[84] Third, we compared the predicted distribution of precipitation around the chasm perimeter with the observed distribution of geology around the chasm perimeter. We assign each land pixel to its nearest pixel on the perimeter of the lake. We then assign each perimeter pixel to its normalized distance along the circumference. Both the perimetermatched geologic data and the perimeter-matched model output are then smoothed using a gaussian kernel of full width at half maximum equal to $5 \%$ of lake circumference. The results are shown in Figure B1. All models produce a broader distribution of snowfall with azimuth and are also biased counterclockwise (from SW to $\mathrm{S}$ ) with respect to the data. This bias is least severe for JUVENTAE HIGH. JUVENTAE_HIGH also shows the best overall fit to the data: by cyclic translation of the smoothed and areanormalized precipitation pattern, we can find the percentage of perturbed patterns that would provide a better least square fit to the smoothed data than our actual model. For the Le Deit et al. [2010] geology, this percentage is 7\% for JUVENTAE_HIGH,12\% for JUVENTAE MED, and 36\% for JUVENTAE LOW. The corresponding values for the Weitz et al. [2010] geology are 10\%, 16\%, and 39\%. Note that the azimuthal distributions shown in Figure B1 are maximum-normalized, not area-normalized.

[85] Finally, we compared the predicted falloff of precipitation with distance from the chasm edge with the observed decrease in the area of channel networks and layered deposits with distance from the chasm edge. Figure B2 shows cumulative distribution functions (CDFs) of geology and precipitation. All geology is found within $60 \mathrm{~km}$ of the chasm edge, but the $e$-folding distance of the cumulative precipitation is significantly larger, $70-110 \mathrm{~km}$. $\sim 95 \%$ of snow is found within $250 \mathrm{~km}$ of the chasm edge.

[86] All these metrics show that the area of precipitation is more extensive than the mapped area of channel networks. This may be an artifact of incomplete preservation and incomplete high-resolution imaging. For example, there is a $25 \mathrm{~km}$-diameter ejecta blanket in our area of highest modeled precipitation that may be obscuring underlying chan-

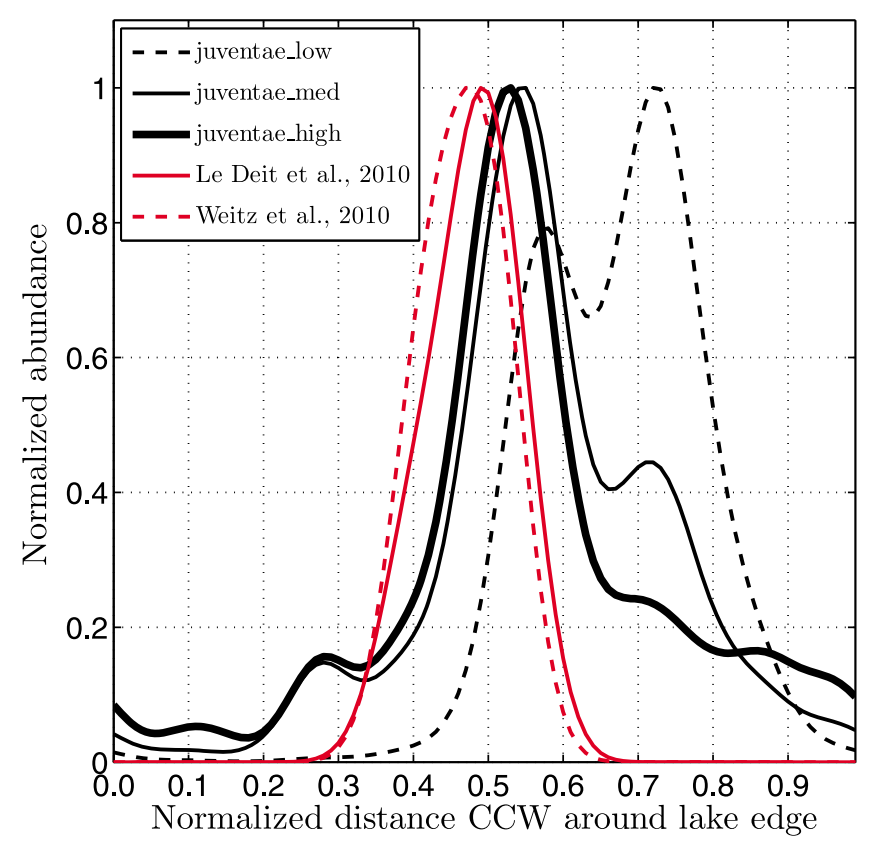

Figure B1. Comparison of azimuth of precipitation with azimuth of mapped channels. 


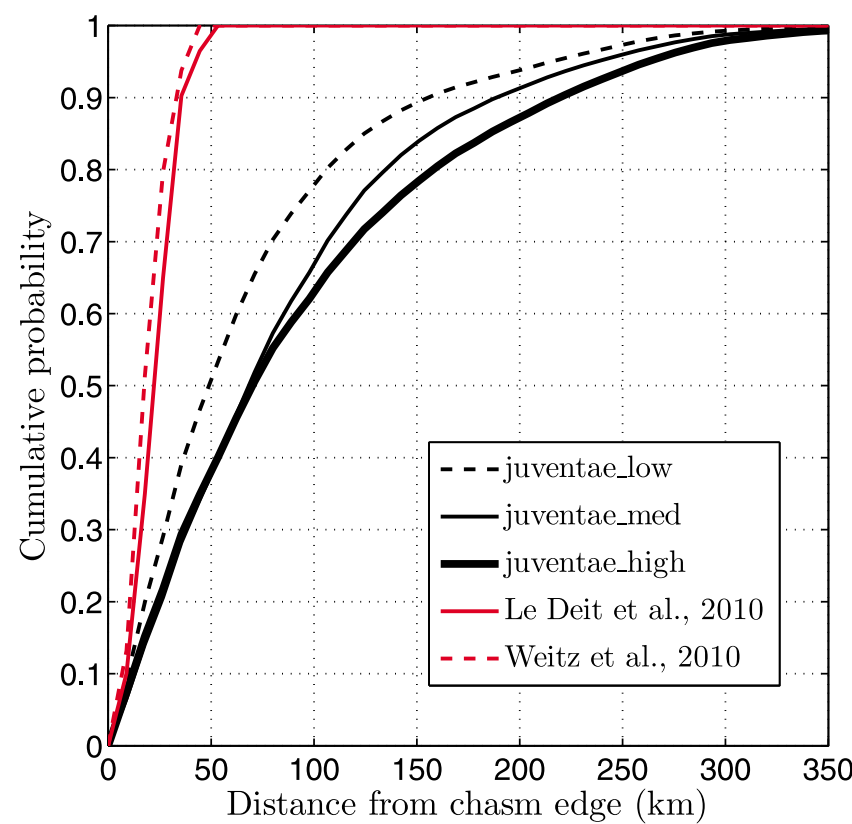

Figure B2. Comparison of falloff of precipitation with falloff of mapped area of channels and layered deposits. Because of an arbitrary mapping cutoff, layered deposits likely extend further than shown.

nels. If precipitation is necessary to form or indurate plateau layered deposits, decline in the precipitation at 100-200 km from the chasm (Figure B2) will create thin, or weakly indurated deposits. These could easily be missed during mapping, removed by the wind, or both. It is possible that the relatively low horizontal resolution of our simulations is artificially broadening our modeled precipitation. Alternatively, there may be a threshold precipitation level to produce layered deposits and channels. For example, sublimation losses may occur during the months between deposition and the beginning of the melt season. These sublimation losses are not included in our simulations, and will thin the snowpack everywhere while reducing the area of remaining snow. Sediment mobilization is very sensitive to small changes in runoff:

$$
Q_{\text {sed }} \propto\left(\tau_{b}-\tau_{\text {crit }}\right)^{3 / 2}
$$

where $Q_{\text {sed }}$ is sediment flux, $\tau_{b} \propto H$ is bed shear stress and is proportional to flow depth $H$, and $\tau_{c r i t}$ is critical bed shear stress. If snow availability limits runoff, this will focus channel incision on areas with high precipitation rates.

\section{Appendix C: Snow Melting Model}

[87] We use a simplified probabilistic melting model to determine the likelihood of melting for the range of orbital conditions possible on pre-modern Mars.

[88] We simulate the temperatures within snowpack using a 1D column model that includes radiative, conductive, and turbulent cooling fluxes. Obliquity $\phi$, eccentricity $e$, longitude of perihelion $L_{a p}$, season $L_{s}$, atmospheric pressure $P_{a t m}$ and geologic age $\tau$ are varied; the ranges for these parameters are given in Table 3. We calculate the annual maximum surface temperature that the snow would reach in the absence of buffering at the melting temperature. If this temperature $>273.15 \mathrm{~K}$, melting should occur sometime during the year. Orbital parameters are not known deterministically for ages $\gg 10$ Ma [Laskar et al., 2004]. However, the probability distribution for orbital elements as a function of time has been calculated [Laskar et al., 2004]. Therefore, we calculate temperatures for all orbital states and multiply each by the probability of that state. The Juventae channels are at $4^{\circ} \mathrm{S}$, and all our calculations are for the equator.

[89] Within the snowpack, material properties are assumed uniform with depth and heat flow is by conduction only. Energy balance for $1 \mathrm{~m}^{2}$ surface area is given by

$$
\begin{gathered}
\left(\frac{1}{\rho c_{p} \Delta z}\right) \frac{\partial T}{\partial t}=-k \frac{\partial T}{\partial z}-\epsilon \sigma T^{4}+L W \downarrow+(1-R C F)(1-\alpha) L \\
-S H_{f r}-S H_{f o}-L H_{f r}-L H_{f o}
\end{gathered}
$$

where $\rho$ is snow density, $c_{p}$ is snow heat capacity, $\Delta z$ is the thickness of the subsurface layer whose upper boundary is the surface ( $2.5 \mathrm{~mm}$ for our nominal parameters), $T$ is the surface temperature, $k$ is snow thermal conductivity, $L W \downarrow$ is downwelling longwave radiation, $R C F$ is the Rayleighscattering correction factor (the difference between insolation reaching the surface in the presence of an atmosphere and in the absence of an atmosphere), $\alpha$ is snow albedo, $\mathrm{SH}_{f r}$ corresponds to free sensible heat losses driven by atmosphere-surface temperature differences, $\mathrm{SH}_{f o}$ corresponds to forced sensible heat losses caused by cool breezes over warm ground, $L H_{f r}$ corresponds to evaporative cooling by free convection when the atmosphere has relative humidity $<1$, and $L H_{f o}$ corresponds to additional evaporative cooling when the wind is nonzero. Table 3 lists parameters used.

[90] The initial condition at the surface is slightly cooler than radiative equilibrium, decaying with an e-folding depth equal to the diurnal skin depth to the energy-weighted diurnal average temperature at depth. For a range of $L_{s}$, we integrate forwards in time for several sols using constant seasonal forcing until the day's maximum surface temperature has converged to $<0.025 \mathrm{~K}$. The subsurface is assumed to be in equilibrium with the radiative forcing for a given $L_{s}$ - month-to-month thermal inertia is not considered.

[91] 1 . We use a $1 \mathrm{D}$ radiative-convective column model of the atmosphere to populate look-up tables of $L W \downarrow$ as a function of surface temperature and surface pressure, and $R C F$ as a function of atmospheric pressure and solar zenith angle. (Both look-up tables were provided by Itay Halevy from output of a column radiative transfer calculation [Halevy et al., 2009]). The atmosphere is assumed to be entirely $\mathrm{CO}_{2} . P_{\text {atm }}$ in our calculations is for the elevation of the Juventae plateau $(+2 \mathrm{~km})$. This is $20 \%$ lower than $P_{a t m}$ at datum.

[92] 2. Our treatment of turbulent fluxes closely follows Dundas and Byrne [2010]. We set

$$
S H_{f r}=0.14\left(T-T_{a}\right) k_{a}\left(\left(\frac{C_{p} \nu_{a} \rho_{a}}{k_{a}}\right)\left(\frac{g_{\text {Mars }}}{\nu_{a}^{2}}\right)\left(\frac{\Delta \rho}{\rho_{a}}\right)\right)^{1 / 3}
$$

where $T_{a}$ is the atmospheric temperature, $k_{a}$ is the atmospheric thermal conductivity, $C_{p}$ is heat capacity of air, $\nu_{a}$ is 
temperature-dependent viscosity of air, $\rho_{a} \propto P_{\text {atm }}$ is density of air, $g_{\text {Mars }}$ is Mars gravity, and $\Delta \rho / \rho_{a}$ is the density contrast between air in equilibrium with the ground and air overlying the surface layer.

[93] $\Delta \rho / \rho_{a}$ is given by

$$
\frac{\Delta \rho}{\rho_{a}}=\frac{\left(m_{c}-m_{w}\right) e_{\text {sat }}\left(1-r_{\text {humidity }}\right)}{m_{c} P_{\text {atm }}}
$$

Here, $m_{c}$ is the molar mass of $\mathrm{CO}_{2}$ and $m_{w}$ is the molar mass of $\mathrm{H}_{2} \mathrm{O}$. r rumidity is the relative humidity of the overlying atmosphere. $e_{\text {sat }}=3.69 \times 10^{12} e^{(-6150 / 7)}$ is the saturation vapor pressure over water ice, from Cuffey and Paterson [2010, equation 4.5]. This agrees to within $1 \%$ with the Hardy [1998] ITS 90 curve fit for $175 \mathrm{~K}<T 298 \mathrm{~K}$. Equation (C3) assumes that water vapor pressure is a minor component of the overall atmospheric pressure, and is simpler but less accurate than equation 10 of Dundas and Byrne [2010].

[94] $T_{a}$ is parameterized as [Dundas and Byrne, 2010]

$$
T_{a}=T_{\min }^{b_{D B}} T^{1-b_{D B}}
$$

where $T_{\min }$ is the coldest (nighttime) surface temperature experienced by the model, and $b_{D B}$ is the Dundas-Byrne ' $\mathrm{b}$ ', a fitting parameter. As $P_{a t m}$ increases the turbulent coupling between the surface and atmosphere becomes stronger, so $b_{D B}$ decreases. We obtain $b_{D B}\left(P_{a t m}\right)$ by fitting to the globally averaged noontime atmosphere-surface temperature difference from GCM models (provided by M. A. Kahre [see also Kahre et al., 2010]).

[95] We let

$$
L H_{f r}=L_{s u b l} 0.14 \Delta \eta \rho_{a} D_{a}\left(\left(\frac{\nu_{a}}{D_{a}}\right)\left(\frac{g_{\text {Mars }}}{\nu_{a}^{2}}\right)\left(\frac{\Delta \rho}{\rho}\right)\right)^{1 / 3}
$$

where $L_{s u b l}$ is the latent heat of sublimation of ice, $\Delta \eta$ is the difference between atmosphere and surface water mass fractions, and $D_{a}$ is the temperature-dependent diffusion coefficient of $\mathrm{H}_{2} \mathrm{O}$ in $\mathrm{CO}_{2}$.

[96] 3. We parameterize

$$
S H_{f o}=\rho_{a} C_{p} u_{\text {wind }} A\left(T_{a}-T\right)
$$

where $C_{p}$ is the atmospheric heat capacity and $u_{\text {wind }}$ is the near-surface wind speed. The drag coefficient $A$ is given by

$$
A=\frac{K_{\text {vonk }}^{2}}{\log \left(z_{\text {anem }} / z_{o}\right)^{2}}
$$

where $K_{\text {vonk }}$ is von Karman's constant, $z_{\text {anem }}$ is anemometer height and $z_{o}$ is surface roughness.

[97] Near-surface wind speed $u_{\text {wind }}$ in Mars GCMs is expected to decrease with increasing pressure and decreasing solar luminosity. The four-season average of European Mars Climate Database (E-MCD) [Millour et al., 2008] "MY24" simulation globally averaged near-surface wind speeds at the present epoch is $3.37 \mathrm{~m} / \mathrm{s}$. We extrapolate this to pressures up to 250 mbar using a logarithmic falloff of mean wind speed with increasing pressure calibrated using GCM model output for pressures between 6 and 80 mbar (supplied by Melinda Kahre). We lower the wind speeds by a factor of 1.08 for the faint young Sun using the ratio of wind speeds for two 60 mbar simulations that differ only in solar luminosity. Simulations also suggest $u_{\text {wind }}$ depends on orbital parameters [Haberle et al., 2003], but we ignore this.

[98] We set

$$
L H_{f o}=L_{\text {subl }} \frac{M_{w}}{k T_{b l}} u_{\text {wind }} e_{\text {sat }}\left(1-r_{\text {humidity }}\right)
$$

where $M_{w}$ is the molecular mass of water, and $k$ is Boltzmann's constant.

[99] The probability of melting depends on snow albedo, which is high for pure snow but much lower for realistic, dust-contaminated snow. Warren and Wiscombe [1980] show that 1000 ppmw of Saharan dust can reduce ice albedo from $>0.9$ to 0.3 . In the words of Langevin et al. [2005, p. 1581], "Water ice is very bright in the visible spectrum when clean, but even a small amount of dust contamination can reduce the albedo to values close to that of the dust itself if the dust grains are embedded in ice grains." Clow [1987] shows that 1000 ppmw dust reduces snow albedo to $0.45-0.6$ for ice grain sizes $400-100 \mu \mathrm{m}$, respectively. This is for precipitation grain sizes in our model; metamorphism will increase grain size and decrease albedo.

[100] Measurements show Mars water ice albedo is low. Dust contamination lowers the albedo of water ice exposed near Mars'south pole today to 0.30 [Titus et al., 2003]. The mean bolometric albedo of bright regions in Mars' North Polar Residual Cap is inferred to be 0.41 from energy balance [Kieffer et al., 1976]. Near-infrared spectroscopy has identified seasonal water ice layers up to $0.2 \mathrm{~mm}$ thick on pole-facing slopes in the Mars low latitudes [Vincendon et al., 2010]. Analysis of the spatial and seasonal dependence of these detections indicates that low-latitude surface water ice has albedo 0.3-0.4 [Vincendon et al., 2010]. Modeling of OMEGA data indicates that water-rich terrains in the South Polar Layered Deposits have albedo 0.3-0.4 [Douté et al. [2007, Figure 7]. Measurements of the gray ring component of Dark Dune Spots in Richardson Crater at $72^{\circ} \mathrm{S}$ show it to be composed of seasonal water ice deposits with an albedo of 0.25-0.30 [Kereszturi et al., 2011]. When melting starts, the albedo of dust-contaminated ice remains low because "when snow melts, the impurities often tend to collect at the surface rather than washing away with the meltwater" [Warren, 1984, p. 178], forming a lag. Water has a low albedo, so stream and melt pond albedo is lower than unmelted surface albedo. Gardner and Sharp [2010] show that 2 ppmw soot can greatly reduce snow albedo. Soot is $200 \times$ more optically effective than Earth crustal dust, and presumably more effective than Mars dust. We use an albedo of 0.28 (the albedo of Mars' dust continents [Mellon et al., 2000]). This corresponds to very dirty snow. Higher albedos will lead to lower melting probabilities (paper 1).

[101] The melting is also sensitive to orbital conditions. For example, at the equator, high eccentricity is more favorable for melting than is low eccentricity (paper 1).

\section{Appendix D: HiRISE Stereo DTMs}

[102] HiRISE DTMs were generated using SOCET SET following USGS recommended procedure [U.S. Geological 
Survey, 2009]: DTM1, Juventae1, PSP 003223 1755/ PSP 003724 1755; DTM2, Juventae2, PSP 004423 1755/ PSP_005412_1755; and DTM3, Ganges1, PSP_005161_1720/ ESP_016237_1720. All DTMs, together with the corresponding orthorectified HiRISE images, can be obtained for unrestricted further use from the lead author.

[103] In addition, we made use of PDS released files for a Juventae plateau stereopair, PSP_003434_1755/ PSP_003579_1755.

[104] Acknowledgments. HiRISE stereo DTMs were produced on the SOCET SET workstation at the SETI Institute, generously made available by Cynthia Phillips. Ross Beyer, Annie Howington-Kraus, Audrie Fennema, and Sarah Mattson assisted with DTM generation. Itay Halevy and Melinda Kahre contributed look-up tables to the melting model. We thank Teresa Segura for advice on starting the project and Inez Fung, Rebecca Williams, Jean-Baptiste Madeleine, Max Rudolph, Ross Irwin, and Leif Karlstrom for useful discussions. We thank Janice Bishop, Keith Harrison, Bob, Grimm, and two anonymous reviewers for commenting on the manuscript. Caleb Fassett drew our attention to inverted channels near Reull Vallis. This work made use of Bin Guan's scripts. We are grateful to the HiRISE team for maintaining a responsive public target request program (HiWish) that was useful for this work. We acknowledge support from Teragrid allocation TG-EAR100023, NASA Science Mission Directorate grant NNX08AN13G, NASA Science Mission Directorate grant NNX09AN18G, and NASA grants to SwRI which funded cloud microphysics capabilities.

\section{References}

Andrews-Hanna, J. C., and R. J. Phillips (2007), Hydrological modeling of outflow channels and chaos regions on Mars, J. Geophys. Res., 112, E08001, doi:10.1029/2006JE002881.

Baker, V. R. (2001), Water and the Martian landscape, Nature, 412, 228-236, doi:10.1038/35084172.

Baker, V. R., R. G. Strom, V. C. Gulick, J. S. Kargel, G. Komatsu, and V. S. Kale (1991), Ancient oceans, ice sheets and the hydrological cycle on Mars, Nature, 352, 589-594, doi:10.1038/352589a0.

Bargery, A. S., and L. Wilson (2010), Dynamics of the ascent and eruption of water containing dissolved $\mathrm{CO}_{2}$ on Mars, J. Geophys. Res., 115, E05008, doi:10.1029/2009JE003403.

Barnhart, C. J., A. D. Howard, and J. M. Moore (2009), Long-term precipitation and late-stage valley network formation: Landform simulations of Parana Basin, Mars, J. Geophys. Res., 114, E01003, doi:10.1029/ 2008JE003122.

Bishop, J. L., et al. (2009), Mineralogy of Juventae Chasma: Sulfates in the light-toned mounds, mafic minerals in the bedrock, and hydrated silica and hydroxylated ferric sulfate on the plateau, J. Geophys. Res., 114, E00D09, doi:10.1029/2009JE003352.

Box, J. E., and K. Ski (2007), Remote sounding of Greenland supraglacial melt lakes: Implications for subglacial hydraulics, J. Glaciol., 53, 257-265, doi:10.3189/1727565077822202883.

Brock, B. W., I. C. Willis, and M. J. Sharp (2006), Measurement and parameterization of aerodynamic roughness length variations at Haut Glacier d'Arolla, Switzerland, J. Glaciol., 52, 281-297, doi:10.3189/ 172756506781828746.

Burr, D. M., et al. (2009), Pervasive aqueous paleoflow features in the Aeolis/Zephyria Plana region, Mars, Icarus, 200, 52-76, doi:10.1016/ j.icarus.2008.10.014.

Burr, D. M., R. M. E. Williams, K. D. Wendell, M. Chojnacki, and J. P. Emery (2010), Inverted fluvial features in the Aeolis/Zephyria Plana region, Mars: Formation mechanism and initial paleodischarge estimates, J. Geophys. Res., 115, E07011, doi:10.1029/2009JE003496.

Carr, M. H. (1995), The Martian drainage system and the origin of valley networks and fretted channels, J. Geophys. Res., 100, 7479-7507, doi:10.1029/95JE00260.

Carr, M. H., and J. W. Head (2003), Basal melting of snow on early Mars: A possible origin of some valley networks, Geophys. Res. Lett., 30(24), 2245, doi:10.1029/2003GL018575.

Carr, M. H., and J. W. Head (2010), Geologic history of Mars, Earth Planet. Sci. Lett., 294, 185-203, doi:10.1016/j.epsl.2009.06.042.

Carr, M. H., and M. C. Malin (2000), Meter-scale characteristics of Martian channels and valleys, Icarus, 146, 366-386, doi:10.1006/icar.2000.6428.

Catling, D. C., et al. (2006), Light-toned layered deposits in Juventae Chasma, Mars, Icarus, 181, 26-51, doi:10.1016/j.icarus.2005.10.020.
Chapman, M. G., et al. (2010a), Amazonian geologic history of the Echus Chasma and Kasei Valles system on Mars: New data and interpretations, Earth Planet. Sci. Lett., 294, 238-255, doi:10.1016/j.eps1.2009.11.034.

Chapman, M. G., et al. (2010b), Noachian-Hesperian geologic history of the Echus Chasma and Kasei Valles system on Mars: New data and interpretations, Earth Planet. Sci. Lett., 294, 256-271, doi:10.1016/j. eps1.2009.11.032.

Clancy, R. T., M. J. Wolff, B. A. Cantor, M. C. Malin, and T. I. Michaels (2009), Valles Marineris cloud trails, J. Geophys. Res., 114, E11002, doi:10.1029/2008JE003323.

Clow, G. D. (1987), Generation of liquid water on Mars through the melting of a dusty snowpack, Icarus, 72, 95-127, doi:10.1016/0019-1035(87) 90123-0.

Clow, G. D. (1994), Minimum discharge rates required for sustained water flow on the Martian surface, Lunar Planet. Sci., 25, 275.

Colaprete, A., O. B. Toon, and J. A. Magalhaes (1999), Cloud formation under Mars Pathfinder conditions, J. Geophys. Res., 104, 9043-9053, doi:10.1029/1998JE900018

Colbeck, S. C. (1976), An analysis of water flow in dry snow, Water Resour. Res., 12(3), 523-527, doi:10.1029/WR012i003p00523.

Coleman, N. M., and V. R. Baker (2007), Evidence that a paleolake overflowed the rim of Juventae Chasma, Mars, Proc. Lunar Planet. Sci. Conf., 38, 1338 .

Conway, S. J., M. P. Lamb, M. R. Balme, M. C. Towner, and J. B. Murray (2011), Enhanced runout and erosion by overland flow at low pressure and subfreezing conditions: experiments and application to Mars, Icarus, 211, 443-457, doi:10.1016/j.icarus.2010.08.026.

Craddock, R. A., and A. D. Howard (2002), The case for rainfall on a warm, wet early Mars, J. Geophys. Res., 107(E11), 5111, doi:10.1029/ 2001JE001505.

Cuffey, K. C., and W. S. B. Paterson (2010), The Physics of Glaciers, 4th ed., Butterworth-Heinemann/Elsevier, Burlington, Mass.

Dehouck, E., et al. (2010), Ismenius Cavus, Mars: A deep paleolake with phyllosilicate deposits, Planet. Space Sci., 58, 941-946, doi:10.1016/j. pss.2010.02.005.

Douté, S., et al. (2007), South Pole of Mars: Nature and composition of the icy terrains from Mars Express OMEGA observations, Planet. Space Sci., 55, 113-133, doi:10.1016/j.pss.2006.05.035.

Dundas, C. M., and S. Byrne (2010), Modeling sublimation of ice exposed by new impacts in the martian mid-latitudes, Icarus, 206, 716-728, doi:10.1016/j.icarus.2009.09.007.

Eichenlaub, V. (1979), Weather and Climate of the Great Lakes Region, Univ. of Notre Dame Press, Notre Dame, Indiana.

Edgett, K. S. (2005), The sedimentary rocks of Sinus Meridiani: Five key observations from data acquired by the Mars Global Surveyor and Mars Odyssey orbiters, Mars, 1, 5-58, doi:10.1555/mars.2005.0002.

Fassett, C. I., and J. W. Head III (2008a), Valley network-fed, open-basin lakes on Mars: Distribution and implications for Noachian surface and subsurface hydrology, Icarus, 198, 37-56, doi:10.1016/j.icarus.2008.06.016.

Fassett, C. I., and J. W. Head III (2008b), The timing of Martian valley network activity: Constraints from buffered crater counting, Icarus, 195 61-89, doi:10.1016/j.icarus.2007.12.009.

Fassett, C. I., et al. (2010), Supraglacial and proglacial valleys on Amazonian Mars, Icarus, 208, 86-100, doi:10.1016/j.icarus.2010.02.021.

Forget, F., et al. (2006), Formation of glaciers on Mars by atmospheric precipitation at high obliquity, Science, 311, 368-371, doi:10.1126/science. 1120335.

Forsberg-Taylor, N. K., A. D. Howard, and R. A. Craddock (2004), Crater degradation in the Martian highlands: Morphometric analysis of the Sinus Sabaeus region and simulation modeling suggest fluvial processes, J. Geophys. Res., 109, E05002, doi:10.1029/2004JE002242.

Gaidos, E., and G. Marion (2003), Geological and geochemical legacy of a cold early Mars, J. Geophys. Res., 108(E6), 5055, doi:10.1029/ 2002JE002000.

Gardner, A. S., and M. J. Sharp (2010), A review of snow and ice albedo and the development of a new physically based broadband albedo parameterization, J. Geophys. Res., 115, F01009, doi:10.1029/2009JF001444.

Golombek, M. P., et al. (2006), Erosion rates at the Mars Exploration Rover landing sites and long-term climate change on Mars, J. Geophys. Res., 111, E12S10, doi:10.1029/2006JE002754.

Grotzinger, J., et al. (2006), Sedimentary textures formed by aqueous processes, Erebus crater, Meridiani Planum, Mars, Geology, 34(12), 1085-1088, doi:10.1130/G22985A.1.

Gulick, V. C., and V. R. Baker (1989), Fluvial valleys and Martian paleoclimates, Nature, 341, 514-516, doi:10.1038/341514a0.

Haberle, R. M., J. B. Pollack, J. R. Barnes, R. W. Zurek, C. B. Leovy, J. R. Murphy, H. Lee, and J. Schaeffer (1993), Mars atmospheric dynamics as simulated by the NASA Ames General Circulation Model: 1. The zonal- 
mean circulation, J. Geophys. Res., 98, 3093-3123, doi:10.1029/ 92JE02946.

Haberle, R. M., et al. (2003), Orbital change experiments with a Mars general circulation model, Icarus, 161, 66-89, doi:10.1016/S00191035(02)00017-9.

Hardy, B. (1998), ITS-90 formulations for vapor pressure, frostpoint temperature, dewpoint temperature, and enhancement factors in the range -100 to $+100 \mathrm{C}$, paper presented at Third International Symposium on Humidity and Moisture, Natl. Phys. Lab., London, April.

Harrison, K. P., and M. G. Chapman (2008), Evidence for ponding and catastrophic floods in central Valles Marineris, Mars, Icarus, 198, 351-364, doi:10.1016/j.icarus.2008.08.003.

Harrison, K. P., and R. E. Grimm (2008), Multiple flooding events in Martian outflow channels, J. Geophys. Res., 113, E02002, doi:10.1029/ 2007JE002951.

Hartmann, W. K. (2005), Martian cratering 8: Isochron refinement and the chronology of Mars, Icarus, 174, 294-320, doi:10.1016/j.icarus 2004.11.023.

Halevy, I., M. T. Zuber, and D. Schrag (2007), A Sulfur Dioxide Climate Feedback on Early Mars, Science, 318, 1903-1907, doi:10.1126/science. 1147039.

Halevy, I., R. T. Pierrehumbert, and D. P. Schrag (2009), Radiative transfer in $\mathrm{CO}_{2}$-rich paleoatmospheres, J. Geophys. Res., 114, D18112, doi:10.1029/2009JD011915.

Head, J. W., III and M. Kreslavsky (2004), Medusae Fossae Formation: Ice-rich airborne dust deposited during periods of high obliquity?, Lunar Planet. Sci., 35th, Abstract 1635.

Howard, A. D., J. M. Moore, R. P. Irwin, and W. E. Dietrich (2007), Boulder Transport Across the Eberswalde Delta, Lunar Planet. Sci. 38, Abstract 1168.

Hynek, B. M., and R. J. Phillips (2003), New data reveal mature, integrated drainage systems on Mars indicative of past precipitation, Geology, 31, 757-760, doi:10.1130/G19607.1.

Hynek, B. M., M. Beach, and M. R. T. Hoke (2010), Updated global map of Martian valley networks and implications for climate and hydrologic processes, J. Geophys. Res., 115, E09008, doi:10.1029/2009JE003548.

Jakosky, B. M., and M. H. Carr (1985), Possible precipitation of ice at low latitudes on Mars during periods of high obliquity, Nature, 315, 559-561, doi:10.1038/315559a0

Jakosky, B. M., B. G. Henderson, and M. T. Mellon (1995), Chaotic obliquity and the nature of the Martian climate, J. Geophys. Res. 100, 1579-1584, doi:10.1029/94JE02801.

Johnson, S. S., M. A. Mischna, T. L. Grove, and M. T. Zuber (2008), Sulfur-induced greenhouse warming on early Mars, J. Geophys. Res., 113, E08005, doi:10.1029/2007JE002962.

Kahre, M. A., et al. (2010), The effect of airborne dust on the stabilization of the early Mars atmosphere against atmospheric collapse, Abstract P53E-1562 presented at 2010 Fall Meeting, AGU, San Francisco, Calif., 13-17 Dec.

Kereszturi, A., M. Vincendon, and F. Schmidt (2011), Water ice in the dark dune spots of Richardson crater on Mars, Planet. Space Sci., 59(1), 26-42, doi:10.1016/j.pss.2010.10.015.

Kieffer, H. H., et al. (1976), Martian north pole summer temperaturesDirty water ice, Science, 194, 1341-1344, doi:10.1126/science. 194.4271.1341.

Kite, E. S., T. I. Michaels, S. Rafkin, M. Manga, and W. E. Dietrich (2011), Localized precipitation and runoff on Mars, J. Geophys. Res., 116, E07002, doi:10.1029/2010JE003783

Kleinhans, M. G. (2005), Flow discharge and sediment transport models for estimating a minimum timescale of hydrological activity and channel and delta formation on Mars, J. Geophys. Res., 110, E12003, doi:10.1029/ 2005JE002521.

Komatsu, G., et al. (2009), Paleolakes, paleofloods, and depressions in Aurorae and Ophir Plana, Mars: Connectivity of surface and subsurface hydrological systems, Icarus, 201, 474-491, doi:10.1016/j.icarus. 2009.01.010.

Kraal, E. R., et al. (2008a), Catalogue of large alluvial fans in Martian impact craters, Icarus, 194, 101-110, doi:10.1016/j.icarus.2007.09.028.

Kraal, E. R., M. van Dijk, G. Postma, and M. G. Kleinhans (2008b), Martian stepped-delta formation by rapid water release, Nature, 451, 973-976, doi:10.1038/nature06615.

Kuiper, K. F., et al. (2008), Synchronizing rock clocks of Earth history, Science, 320, 500-504, doi:10.1126/science.1154339.

Laskar, J., et al. (2004), Long term evolution and chaotic diffusion of the insolation quantities of Mars, Icarus, 170, 343-364, doi:10.1016/ j.icarus.2004.04.005.

Langevin, Y., et al. (2005), Summer evolution of the north polar cap of Mars as observed by OMEGA/Mars Express, Science, 307, 1581-1584, doi:10.1126/science. 1109438 .
Le Deit, L., et al. (2010), Morphology, stratigraphy, and mineralogical composition of a layered formation covering the plateaus around Valles Marineris, Mars: Implications for its geological history, Icarus, 208 684-703, doi:10.1016/j.icarus.2010.03.012.

Lefort, A., D. M. Burr, R. A. Beyer, and A. D. Howard (2011), Topographic post-formation modifications of inverted fluvial features in the Western Medusae Fossae Formation, Mars, Proc. Lunar. Planet. Sci. Conf., 42, 2418 .

Levy, J. S., and J. W. Head III (2005), Evidence for remnants of ancient ice-rich deposits: Mangala Valles outflow channel, Mars, Terra Nova, 17, 503-509, doi:10.1111/j.1365-3121.2005.00642.x.

Lewis, K. W., et al. (2008), Quasi-periodic bedding in the sedimentary rock record of Mars, Science, 322, 1532-1535, doi:10.1126/science.1161870.

Lewis, K. W., et al. (2010), Global significance of cyclic sedimentary deposits on Mars, Proc. Lunar Planet. Sci. Conf., 41, 2648.

Lüthje, M., et al. (2006), Modelling the evolution of supraglacial lakes on the West Greenland ice-sheet margin, J. Glaciol., 52, 608-618, doi: $10.3189 / 172756506781828386$.

Madeleine, J.-B., et al. (2009), Amazonian northern mid-latitude glaciation on Mars: A proposed climate scenario, Icarus, 203, 390-405, doi:10.1016/j.icarus.2009.04.037.

Malin, M.C., and K. S. Edgett (2003), Evidence for persistent flow and aqueous sedimentation on early Mars, Science, 302, 1931-1934 doi:10.1126/science.1090544.

Malin, M. C., et al. (2010), An overview of the 1985-2006 Mars Orbiter Camera science investigation, Mars, 5, 1-60, doi:10.1555/mars. 2010.0001

Mangold, N., and V. Ansan (2006), Detailed study of an hydrological system of valleys, a delta and lakes in the southwest Thaumasia region, Mars, Icarus, 180, 75-87, doi:10.1016/j.icarus.2005.08.017.

Mangold, N., et al. (2004), Evidence for precipitation on Mars from dendritic valleys in the Valles Marineris area, Science, 305, 78-81, doi:10.1126/science. 1097549

Mangold, N., V. Ansan, P. Masson, C. Quantin, and G. Neukum (2008), Geomorphic study of fluvial landforms on the northern Valles Marineris plateau, Mars, J. Geophys. Res., 113, E08009, doi:10.1029/ 2007JE002985

Markowski, P., and Y. Richardson (2010), Mesoscale Meteorology in Midlatitudes, John Wiley, New York, doi:10.1002/9780470682104.

McKenzie, D., and F. Nimmo (1999), The generation of Martian floods by the melting of ground ice above dykes, Nature, 397, 231-233, doi: $10.1038 / 16649$

McLennan, S. M., and J. P. Grotzinger (2008), The sedimentary rock cycle of Mars, in The Martian Surface: Composition, Mineralogy, and Physical Properties, edited by J. Bell, pp. 541-577, Cambridge University Press, Cambridge, U. K., doi:10.1017/CBO9780511536076.025

Mellon, M. T., and B. M. Jakosky (1995), The distribution and behavior of Martian ground ice during past and present epochs, J. Geophys. Res., 100, 11,781-11,799, doi:10.1029/95JE01027.

Mellon, M. T., et al. (2000), High-resolution thermal inertia mapping from the Mars Global Surveyor Thermal Emission Spectrometer, Icarus, 148 437-455, doi:10.1006/icar.2000.6503.

Metz, J. M., J. P. Grotzinger, D. Mohrig, R. Milliken, B. Prather, C. Pirmez, A. S. McEwen, and C. M. Weitz (2009), Sublacustrine depositional fans in southwest Melas Chasma, J. Geophys. Res., 114, E10002, doi:10.1029/2009JE003365.

Michaels, T. I., A. Colaprete, and S. C. R. Rafkin (2006), Significant vertical water transport by mountain-induced circulations on Mars, Geophys. Res. Lett., 33, L16201, doi:10.1029/2006GL026562.

Milliken, R. E., et al. (2008), Opaline silica in young deposits on Mars, Geology, 36, 847-850, doi:10.1130/G24967A.1.

Millour, E., F. Forget, and S. R. Lewis (2008), Mars Climate Database v4.3 detailed design document, http://www-mars.lmd.jussieu.fr/, Eur. Space Agency, Eur. Space Res. and Technol. Cent, Noordwijk, Netherlands.

Mischna, M. A., M. I. Richardson, R. J. Wilson, and D. J. McCleese (2003), On the orbital forcing of Martian water and $\mathrm{CO}_{2}$ cycles: A general circulation model study with simplified volatile schemes, J. Geophys. Res., 108(E6), 5062, doi:10.1029/2003JE002051.

Möhlmann, D. T. F., et al. (2009), Fog phenomena on Mars, Planet. Space Sci., 57, 1987-1992, doi:10.1016/j.pss.2009.08.003.

Montgomery, D. R., and K. B. Gran (2001), Downstream variations in the width of bedrock channels, Water Resour. Res., 37(6), 1841-1846, doi:10.1029/2000WR900393.

Mouginot, J., et al. (2010), The 3-5 MHz global reflectivity map of Mars by MARSIS/Mars Express: Implications for the current inventory of subsurface $\mathrm{H}_{2} \mathrm{O}$, Icarus, 210, 612-625, doi:10.1016/j.icarus.2010.07.003.

Murchie, S. L., et al. (2009a), A synthesis of Martian aqueous mineralogy after 1 Mars year of observations from the Mars Reconnaissance Orbiter, J. Geophys. Res., 114, E00D06, doi:10.1029/2009JE003342. 
Murchie, S. L., et al. (2009b), Evidence for the origin of layered deposits in Candor Chasma, Mars, from mineral composition and hydrologic modeling, J. Geophys. Res., 114, E00D05, doi:10.1029/2009JE003343.

Perron, J. T., M. P. Lamb, C. D. Koven, I. Y. Fung, and E. Yager (2006), Valley formation and methane precipitation rates on Titan, J. Geophys. Res., 111, E11001, doi:10.1029/2005JE002602.

Pielke, R. A. (2002), Mesoscale Meteorological Modeling, 2nd ed., Academic, San Diego, Calif.

Pielke, R. A., and Y. Mahrer (1978), Verification analysis of Universityof-Virginia 3-dimensional mesoscale model prediction over south Florida for 1 July 1973, Mon. Weather Rev., 106, 1568-1589, doi:10.1175/15200493(1978) $106<1568$ :VAOTUO>2.0.CO;2.

Pielke, R. A., et al. (1992), A comprehensive meteorological modeling system-RAMS, Meteorol. Atmos. Phys., 49, 69-91, doi:10.1007/ BF01025401.

Plesko, C. S. (2009), Energy partitioning in an impact-generated greenhouse event as a function of impactor size, in automated feature detection and hydrocode modeling of impact-related structures on Mars, doctoral thesis, Univ. of Calif., Santa Cruz.

Pollack, J. B., J. F. Kasting, S. M. Richardson, and K. Poliakoff (1987), The case for a wet, warm climate on early Mars, Icarus, 71, 203-224, doi:10.1016/0019-1035(87)90147-3.

Postberg, F., S. Kempf, J. Schmidt, N. Brilliantov, A. Beinsen, B. Abel, U. Buck, and R. Srama (2009), Sodium salts in E-ring ice grains from an ocean below the surface of Enceladus, Nature, 459, 1098-1101, doi: $10.1038 /$ nature 08046

Quantin, C., P. Allemand, N. Mangold, G. Dromart, and C. Delacourt (2005), Fluvial and lacustrine activity on layered deposits in Melas Chasma, Valles Marineris, Mars, J. Geophys. Res., 110, E12S19, doi:10.1029/2005JE002440.

Rafkin, S. C. R., and T. I. Michaels (2003), Meteorological predictions for 2003 Mars Exploration Rover high-priority landing sites, J. Geophys. Res., 108(E12), 8091, doi:10.1029/2002JE002027.

Rafkin, S. C. R., R. M. Haberle, and T. I. Michaels (2001), The Mars Regional Atmospheric Modeling System (MRAMS): Model description and selected simulations, Icarus, 151, 228-256, doi:10.1006/ icar.2001.6605.

Roach, L. H., et al. (2010), Hydrated mineral stratigraphy of Ius Chasma, Valles Marineris, Icarus, 206, 253-268, doi:10.1016/j.icarus. 2009.09.003.

Santiago, D. L., A. Colaprete, R. M. Haberle, L. C. Sloan, and E. Asphaug (2005), Outflow channels influencing Martian climate: Global circulation model simulations with emplaced water, Lunar Planet. Sci., 36th, Abstract 1787 .

Santiago, D. L., A. Colaprete, R. M. Haberle, L. C. Sloan, and E. Asphaug (2006), Clouds, cap, and consequences: Outflow events and Mars Hesperian climate, Lunar Planet. Sci., 37th, Abstract 1484.

Scambos, T., C. Hulbe, and M. Fahnestock (2003), Climate-induced ice shelf disintegration in the Antarctic peninsula, in Antarctic Peninsula Climate Variability: Historical and Paleoenvironmental Perspectives, Antarct. Res. Ser., vol. 79, edited by E. Domack, et al., pp. 79-92, AGU, Washington, D. C.

Segura, T. L., and T. Colaprete (2009), Global modeling of impact-induced greenhouse warming on Early Mars, Lunar Planet. Sci., 40, 1056.

Segura, T. L., O. B. Toon, T. Colaprete, and K. Zahnle (2002), Environmental Effects of Large Impacts on Mars, Science, 298, 1977-1980, doi: $10.1126 /$ science. 1073586

Segura, T. L., O. B. Toon, and T. Colaprete (2008), Modeling the environmental effects of moderate-sized impacts on Mars, J. Geophys. Res., 113 E11007, doi:10.1029/2008JE003147.

Shean, D. E. (2010), Candidate ice-rich material within equatorial craters on Mars, Geophys. Res. Lett., 37, L24202, doi:10.1029/2010GL045181.

Shean, D. E., J. W. Head III, J. L. Fastook, and D. R. Marchant (2007), Recent glaciation at high elevations on Arsia Mons, Mars: Implications for the formation and evolution of large tropical mountain glaciers, J. Geophys. Res., 112, E03004, doi:10.1029/2006JE002761.

Smith, M. D. (2002), The annual cycle of water vapor on Mars as observed by the Thermal Emission Spectrometer, J. Geophys. Res., 107(E11), 5115, doi:10.1029/2001JE001522.

Smith, M. D., (2004), Interannual variability in TES atmospheric observations of Mars during 1999-2003, Icarus, 167, 148-165, doi:10.1016/j. icarus.2003.09.010
Spiga, A., and F. Forget (2009), A new model to simulate the Martian mesoscale and microscale atmospheric circulation: Validation and first results, J. Geophys. Res., 114, E02009, doi:10.1029/2008JE003242.

Titus, T. N., H. H. Kieffer, and P. R. Christensen (2003), Exposed water ice discovered near the south pole of Mars, Science, 299, 1048-1051, doi:10.1126/science. 1080497 .

Toon, O. B., et al. (1988), A multidimensional model for aerosols: Description of computational analogs, J. Atmos. Sci., 45, 2123-2144, doi:10.1175/1520-0469(1988)045<2123:AMMFAD>2.0.CO;2.

Toon, O. B., C. P. McKay, T. P. Ackerman, and K. Santhanam (1989), Rapid calculation of radiative heating rates and photodissociation rates in inhomogeneous multiple scattering atmospheres, J. Geophys. Res., 94, 16,287-16,301, doi:10.1029/JD094iD13p16287.

Toon, O. B., T. Segura, and K. Zahnle (2010), The formation of Martian river valleys by impacts, Annu. Rev. Earth Planet. Sci., 38, 303-322, doi:10.1146/annurev-earth-040809-152354.

U.S. Geological Survey (2009), USGS Astrogeology Science Center Tutorial: Stereo Processing using HiRISE Stereo Imagery ISIS3 and SOCET SET, Reston, Va., June, (Available at http://webgis.wr.usgs.gov/pigwad/ tutorials/socetset/SocetSet4HiRISE.htm.)

van Eaton, A., et al. (2010), Microphysical controls on ascent of water-rich ash clouds from supereruptions, Abstract V13C-2375 presented at 2010 Fall Meeting, AGU, San Francisco, Calif., 13-17 Dec.

Vincendon, M., F. Forget, and J. Mustard (2010), Water ice at low to midlatitudes on Mars, J. Geophys. Res., 115, E10001, doi:10.1029/ 2010JE003584.

Wang, C.-Y., M. Manga, and C. Wong (2005), Floods on Mars released from groundwater by impact, Icarus, 175, 551-555, doi:10.1016/j.icarus. 2004.12.003.

Warner, N., et al. (2010), Hesperian equatorial thermokarst lakes in Ares Vallis as evidence for transient warm conditions on Mars, Geology, 38, 71-74, doi:10.1130/G30579.1.

Warren, S. G. (1984), Impurities in snow-Effects on albedo and snowmelt, Ann. Glaciol., 5, 177-179.

Warren, S. G., and W. J. Wiscombe (1980), A model for the spectral albedo of snow. II: Snow containing atmospheric aerosols, J. Atmos. Sci., 37 , 2734-2745, doi:10.1175/1520-0469(1980)037<2734:AMFTSA > 2.0.CO;2.

Watters, T. R., et al. (2007), Radar sounding of the Medusae Fossae formation Mars: Equatorial ice or dry, low-density deposits?, Science, 318, 1125-1128, doi:10.1126/science. 1148112 .

Weitz, C. M., et al. (2008), Light-toned strata and inverted channels adjacent to Juventae and Ganges chasmata, Mars, Geophys. Res. Lett., 35, L19202, doi:10.1029/2008GL035317.

Weitz, C. M., et al. (2010), Mars Reconnaissance Orbiter observations of light-toned layered deposits and associated fluvial landforms on the plateaus adjacent to Valles Marineris, Icarus, 205, 73-102, doi:10.1016/j.icarus.2009.04.017.

Williams, R. M. E. (2007), Global spatial distribution of raised curvilinear features on Mars, Proc. Lunar Planet. Sci. Conf., 38, 1821.

Williams, R. M. E., and M. C. Malin (2008), Sub-kilometer fans in Mojave Crater, Mars, Icarus, 198, 365-383, doi:10.1016/j.icarus.2008.07.013.

Williams, R. M. E., R. J. Phillips, and M. C. Malin (2000), Flow rates and duration within Kasei Valles, Mars: Implications for the formation of a Martian Ocean, Geophys. Res. Lett., 27(7), 1073-1076, doi:10.1029/ 1999GL010957.

Williams, R. M. E., M. C. Malin, and K. S. Edgett (2005), Remnants of the courses of fine-scale, precipitation-fed runoff streams preserved in the Martian rock record, Proc. Lunar Planet. Sci. Conf., 36, 1173.

Williams, R. M. E., T. C. Chidsey Jr., and D. E. Eby (2007), Exhumed paleochannels in central Utah - analogs for raised curvilinear features on Mars, in Central Utah-Diverse Geology of a Dynamic Landscape, edited by G. C. Willis et al., Utah Geol. Assoc. Publ., 36, 220-235.

Williams, R. M. E., et al. (2009), Evaluation of paleohydrologic models for terrestrial inverted channels: Implications for application to Martian sinuous ridges, Geomorphology, 107, 300-315, doi:10.1016/j.geomorph. 2008.12.015.

W. E. Dietrich, E. S. Kite, and M. Manga, Department of Earth and Planetary Science, University of California, 307 McCone Hall 4767 Berkeley, CA 94720, USA. (kite@berkeley.edu)

T. I. Michaels and S. Rafkin, Department of Space Studies, Southwest Research Institute, 1050 Walnut St., Ste. 400, Boulder, CO 80302, USA. 